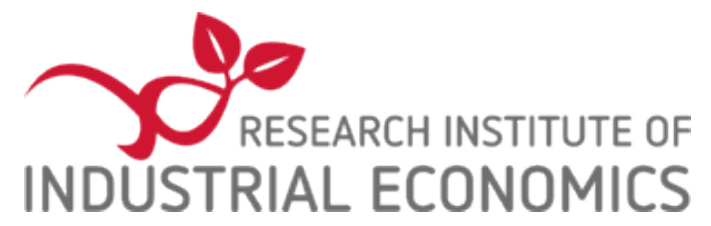

IFN Working Paper No. 1110, 2016

\title{
Asymmetric Information in Auctions: Are Resellers Better Appraisers?
}

Nikita Koptyug 


\title{
Asymmetric Information in Auctions: Are Resellers Better Appraisers?*
}

\author{
Nikita Koptyug ${ }^{\dagger}$
}

February 2016

\begin{abstract}
This paper shows that in online car auctions, resellers are better at appraising the value of the cars they are bidding on than are consumers. Using a unique data set of online car auctions, I show that differences in bidding behavior between resellers and consumers can be explained by heterogeneity in the accuracy of bidders' private signals and heterogeneity in the dispersion of private value components. I use the asymmetric ascending auction model of Hong and Shum (2003) to quantify the differences between resellers and consumers, finding that the dispersion of reseller value signals is roughly half that of consumers and simulate three different counterfactual scenarios - one in which consumers are provided with more information, one in which consumers are subsidized and one in which consumers are allowed into all-reseller auctions. Finally, I argue that the asymmetry in signal precision stems not from asymmetric information regarding the technical characteristics of a car but rather from uncertainty about the car's resale value.
\end{abstract}

JEL Codes: L62, C51, D44, D82

Key words: Ascending (English) Auctions, Asymmetric Auctions, Experience, Learning, Winner's Curse, Bid Shading, Signal Precision, Resellers

*I would like to thank Tore Ellingsen, Richard Friberg, Cristian Huse, Robert H. Porter, Romeo Tedongap and Tomas Thörnqvist. I would also like to thank participants at the IIOC, EARIE, CEPR Applied Industrial Organization Summer School and SSE brown bag seminars. I gratefully acknowledge financial support from The Foundation of Banking Research, the Jan Wallander and Tom Hedelius Foundation and the Marianne and Marcus Wallenberg Foundation.

${ }^{\dagger}$ Research Institute of Industrial Economics. Email address: nikita.koptyug@ifn.se. Correspondence address: Research Institute of Industrial Economics, Grevgatan 34, Box 55665, 10215 Stockholm, Sweden. 


\section{Introduction}

In an influential study, Akerlof (1970) showed that asymmetries in information between the buyers and sellers of cars may cause a breakdown in the used car market. Unscrupulous sellers will want to take advantage of knowing whether a car is a "lemon" - a bitter and unpleasant experience for the buyer - driving out good quality cars altogether or completely impeding transactions between buyers and seller.

In auctions, in which a good is sold by a seller to many potential buyers, asymmetries may exist not only between the buyers and the sellers, but also across buyers; in oil drainage lease auctions conducted by the U.S. government, studies find firms having drilled for oil in regions close to the location of the auctioned lease to behave in ways consistent with their having a clearer idea about the profitability of a given location than outside firms (Hendricks and Porter (1988), Hendricks, Porter and Wilson (1994)). In a study of Mauritian slave auctions, Dionne, St-Amour and Vencatachellum (2009) find that not only is there evidence of asymmetric information between bidders but that this asymmetry leads to adverse selection in choosing which slaves to compete for.

In car auctions, there are multiple ways asymmetries can arise; sellers may strategically choose how much information to release about the quality of the cars (Lewis, 2011) impacting the revenues generated as well as how well the market works (Tadelis and Zettelmeyer, 2011). Furthermore, although there are car auctions in which only professionals, or resellers, participate (as in e.g. Tadelis and Zettelmeyer, 2011), there are auctions in which there are arguably both consumers and resellers. Although information is relevant only in cases in which bidder valuations are interdependent, with one bidder's information potentially influencing that of another, even in independent private value settings the presence of resellers has been theoretically shown to induce interdependence between bidder valuations, potentially increasing the importance of differences in information (Haile, 2001).

In this paper, I build on the existing literature by studying the differences between consumers and resellers focusing not only on whether asymmetries in information exist, but also on quantifying them and providing potential explanations for the sources of such asymmetries.

I start by presenting the asymmetric ascending auction model of Hong and Shum (2003), using it to show the implications of asymmetric information on bidder behavior. Being highly general, the model produces different implications for bidder behavior depending on whether the auction is a pure independent value auction - in which values are independent across bidders, common value auction - in which the value is the same to all bidders - or an auction in which both of these components are important. For auctions in which the independent private value has the most importance, the model predicts that average bids will fall with increased signal precision but will be largely independent of the number of bidders participating in the auction. On the other hand, in an auction in which the common value component is of most importance, bidders strategically "shade", or lower, their bids in order to account for the winner's curse - the possibility of overpaying by not accounting for the fact that the winner likely had the most optimistic signal. In such auctions, by correcting for the winner's curse, bidders cause a decline in the average bid as the number of bidders in an auction increases (Milgrom and Weber, 1982, Athey and Haile, 2002). As one improves the signal of bidders in common value auctions, bidders will be much less likely to overpay and will have a lower incentive to shade their bids as the number of auction participants increases.

Using these predictions, I show reduced-form evidence from a unique data set of roughly six thousand online car auctions that these auctions seem to have a sizable common value component 
and that bidders which are likely to be car resellers seem to lower, or shade, their bids less than bidders that have won only one, or at most two, auctions. Consistent with the predictions of the theoretical model, this suggests that resellers are better at appraising the value of the cars they are bidding on, having more precise signals, than are consumers.

By estimating the asymmetric ascending auction model of Hong and Shum (2003), I quantify the extent to which resellers' signals are more precise than that of consumers; I find that the dispersion in resellers' value estimates is roughly half that of consumers. As a consequence of being better able to estimate the value of the auctioned cars, the model predicts that resellers become less reliant on the estimates of others. Due to their more precise signals, resellers do not need to adjust their beliefs as much during the course of the auctions, lowering their bids less as new information becomes available through the bidding process. I also show that due to asymmetries in signal precision, when a bidder with a precise signal drops out, the remaining bidders adjust their beliefs more than when a bidder with an imprecise signal drops out. In other words, bidders do not treat all information equally, with more precise information being more important than less precise information.

Using the estimated model parameters, I simulate and evaluate three different counterfactual scenarios. Firstly, I simulate the effect of providing consumers with additional information, thereby improving their signal accuracy to that of resellers, and find that this has a positive impact on revenues as compared to auctions in which all bidders are just normal consumers. Secondly, I simulate the effect of subsidizing the consumers while at the same time charging resellers a fee. I find that subsidizing consumers has a non-trivial impact on expected revenues, with there being an increase in expected revenues in auctions with relatively few participants and a decrease for auctions with relatively many participants. Furthermore, subsidizing consumers has a positive effect on the expected bids in the auctions, regardless of the number of participants. Finally, I simulate the effect of allowing consumers into all-resellers auctions and find that this leads to an increase in expected revenues only in the case when this increases the expected number of bidders in an auction. If instead consumers crowd out resellers, or resellers choose not to participate after the introduction of consumers, there will be a decline in expected bids and revenues.

Having shown that resellers do in actual fact have more precise signals than do consumers, I argue that because the online auction house provides a very detailed mechanical assessment of each auctioned car, differences in assessing unobservable car quality are unlikely to be the source of the asymmetries in signal precision between resellers and consumers. By showing that more experienced, larger resellers seem to have better information than less experienced, small resellers, and that resellers in general have more precise signals about more popular cars, I argue instead that resellers know the resale, or common component, value better than do consumers, understanding the price a given car can fetch on the secondary market.

This paper is organized as follows; In Section 2, I present the structural asymmetric ascending auction model of Hong and Shum (2003). In Section 3, I present the data used in this study, descriptive statistics together with reduced-form evidence of resellers bidding in a manner consistent with their having more precise signals than consumers. In Section 4, I discuss the identification of the model and its parameters, as well as the simulation procedure used to estimate the parameters from the data. In Section 5, I present and discuss the results and in Section 6 I discuss the revenue consequences of signal precision. In Section $7 \mathrm{I}$ argue that the asymmetric information is not about the car itself as much as the resale value. In Section 8 I present the results of various robustness tests with Section 9 concluding. 


\section{Model}

In the simplest setting, such as a pure independent private value or pure common value auctions, it may be possible to intuitively understand how bidder behavior will be affected by differences in the ability to value the object being auctioned. The situation becomes more complex if there are not only informational differences between the types; for instance, it is reasonable to assume that consumers have a higher private valuation of certain car components, valuing such things as a specific color or the upholstery of the interior. Resellers, on the other hand, are likely to be more interested in the resale value of the car, focusing instead on the brand or overall quality.

To disentangle these different asymmetries, as well as quantifying them, I apply the asymmetric ascending auction model of Hong and Shum (2003). Incorporating both private value and common value components, the model is very well suited to study car auctions, arguably incorporating both types of components due to the presence of both consumers as well as resellers. Furthermore, the model allows asymmetries among bidders of a given type, for instance, allowing one consumer to differ from another consumer both in preferences for different car characteristics as well as the ability to determine the value of the common value or resale component.

Despite there being a wide range of models proposed to study data from online auction house eBay, these models are theoretically unsuitable due to the nature of the auctions' ending rules. eBay auctions have a predetermined ending time, publicly displayed to all bidders, known as a "hard" close. The auctions studied in this paper end only after a period of inactivity, something known instead as a "soft" close. This difference is seemingly small, but has implications for how bidders in the two different types of auctions will behave; eBay auctions are prone to a phenomenon known as "sniping" whereby the majority of bids are submitted very close to the end of the auction, something that looses strategic value in "soft"-close auctions. 1

In this section, I will present the asymmetric ascending auction model of Hong and Shum (2003) and discuss the implications of asymmetries in information on bidder behavior. In Section 3, I will try to observe behavior consistent with these prediction in the data using reduced-form methods.

\subsection{Equilibrium Bidding}

Consider an auction with $N$ known bidders. The auction proceeds in rounds with a new bidder dropping out irrevocably in every round $k$. Let bidders be indexed by the round in which they drop out: $2^{2}$ bidder $N$ drops out in round 0 , at price $P_{0}$, and bidder $N-k$ drops out in round $k$ at price $P_{k}$, with bidder 1 finally winning the auction at the final observed dropout price $P_{N-2}$.

Each bidder $i=1, \ldots, N$ attaches a value of $V_{i}$ to the object being auctioned. The valuation is unobservable to each bidder and instead, each bidder observes a private, noisy signal $X_{i}$ about their value $V_{i}$.

In round $k$, as the $N-k+1^{\text {st }}$ bidder has already dropped out, the remaining $N-k$ bidders can invert the dropout price $P_{N-k+1}$ to learn the private information $X_{N-k+1}$ of that bidder. In common value auctions, this information is useful to the remaining bidders as they can use it to update their beliefs about their own valuation.

\footnotetext{
${ }^{1}$ Sniping is the practice of trying to place a bid as late as possible so as to avoid revealing private information to other participants. As there is no predetermined or fixed ending time in soft-close auctions, no matter what time you choose to submit your bid, there will always be a minimum amount of time remaining until the auction ends. For a more extensive discussion on sniping and auction ending rules see e.g. Roth and Ockenfels (2002).

${ }^{2}$ This is done without loss of generality.
} 
A Bayesian-Nash equilibrium of the asymmetric ascending auction game is given by bid functions $\beta_{i}^{k}\left(X_{i} ; \Omega_{k}\right)$ for each bidder $i=1, \ldots, N$ and every round of the auction $k$. Each bid function $\beta_{i}^{k}\left(X_{i} ; \Omega_{k}\right)$ determines the price above which player $i$ should drop out in round $k$ given the player's private signal $X_{i}$ and $\Omega_{k}$, the collection of $k-1$ signals observed prior to round $k !^{3}$ Denote the collection of equilibrium bid functions for player $i$ as

$$
\mathbb{B}_{i}=\left\{\beta_{i}^{0}\left(X_{i} ; \Omega_{0}\right), \ldots, \beta_{i}^{N-2}\left(X_{i} ; \Omega_{N-2}\right)\right\}
$$

Assume that for all bidders $i=1, \ldots, N$ the bidding functions $\mathbb{B}_{j}$ of all other players $j \neq i$ are common knowledge.

Assume further that

(A1) The conditional expectation $E\left[V_{i} \mid X_{1}, \ldots, X_{N}\right]$ is strictly increasing in signals $X_{i}$ for each bidder $i=1, . ., N$

(A2) The solution of the $N-k$ unknown variables, $X_{1}, \ldots, X_{N-k}$, in the equation system given by

$$
\begin{aligned}
E\left[V_{1} \mid X_{1}, \ldots, X_{N-k} ; X_{N-k+1}, \ldots, X_{N}\right] & =P \\
E\left[V_{N-k} \mid X_{1}, \ldots, X_{N-k} ; X_{N-k+1}, \ldots, X_{N}\right] & =P
\end{aligned}
$$

is unique and strictly increasing in the given parameter $P$, for all possible realizations of $X_{N-k+1}, \ldots, X_{N}$.

Proposition 1 (Hong and Shum, 2003) Given assumptions A1 and A2, there exists an increasing-strategy Bayesian-Nash Equilibrium of the asymmetric English auction for which the strategies are defined recursively. In round $k$ :

$$
\beta_{i}^{k}\left(X_{i} ; \Omega_{k}\right)=E\left[V_{i} \mid X_{i} ; X_{j}=\left(\beta_{j}^{k}\right)^{-1}\left(\beta_{i}^{k}\left(X_{i} ; \Omega_{k}\right)\right), j=1, \ldots, N, j \neq i, \Omega_{k}\right]
$$

for the bidders $i=1, \ldots, N-k$ remaining active in round $k$, where $\Omega_{k}$ denotes the public information set consisting of the signals of the bidders $N-k+1, \ldots, N$ who have dropped out prior to round $k$, i.e.,

$$
\Omega_{k}=\left\{X_{j}=\left(\beta_{j}^{N-j}\right)^{-1}\left(P_{N-j}\right), j=N-k+1, \ldots, N\right\}
$$

Proof: See Hong and Shum (2003), p331.

Let the valuation of bidder $i$ have a multiplicative form given by $V_{i}=A_{i} \times V$ where $A_{i}$ is a bidder-specific private value component and $V$ is a component common to all bidders in the auction. Let $A_{i}$ and $V$, both unobserved by all bidders, be independently log-normally distributed:4

$$
\begin{aligned}
& \ln V=v=m+\varepsilon_{v} \sim N\left(m, r_{0}^{2}\right) \\
& \ln A_{i}=a_{i}=\bar{a}_{i}+\varepsilon_{a_{i}} \sim N\left(\bar{a}_{i}, t_{i}^{2}\right)
\end{aligned}
$$

\footnotetext{
${ }^{3}$ One can think of $\Omega_{k}$ as being either the collection of $k-1$ dropout prices or inverted private signals of the $k-1$ bidders that have dropped out prior to round $k$.

${ }^{4}$ By lemma 1 of Hong and Shum (2003), p335, this log-normal log-additive specification satisfies assumptions A1 and A2, ensuring existence of an increasing-strategy Bayesian-Nash Equilibrium of the asymmetric English auction.
} 
The mean parameters, $\bar{a}_{i}, m$, can be thought of as governing the magnitude of the average bid within auctions whereas $t_{i}^{2}$ can be thought of as governing the dispersion of those bids. The variance of the common value component $r_{0}^{2}$, governs the dispersion of bids across auctions.

Each bidder observes a private noisy signal $X_{i}$ of the value $V_{i}$, given by $X_{i}=V_{i} \exp \left\{s_{i} e_{i}\right\}$, where $e_{i}$ is a normally distributed unobserved error term with a mean of zero and variance of one. The variance of the noise, $s_{i}^{2}$, can be thought of as the informativeness or accuracy of signal $X_{i}$, with a higher precision potentially affecting the behavior of all bidders in an auction. As in the study of asymmetric information in Mauritian slave auctions by Dionne et al. (2009), this parameter will capture the degree of asymmetry in signal precision, with the degree of precision being indicative of the amount of information that any bidder has about the value of the object being auctioned.

Let the parameters

$$
\left\{\left\{\bar{a}_{i}\right\}_{i=1}^{N},\left\{t_{i}^{2}\right\}_{i=1}^{N}, m, r_{0}^{2},\left\{s_{i}^{2}\right\}_{i=1}^{N}\right\}
$$

be denoted by $\theta$ and assumed to be common knowledge among all bidders.

Under the assumption of log-normality of the errors, the conditional expectation given under A1 will have the general form given by

$$
E\left[V_{i} \mid X_{1}, \ldots, X_{N-k} ; X_{N-k+1}, \ldots, X_{N}\right]=\exp \left\{E\left(v_{i} \mid x_{1}, \ldots, x_{N}\right)+\frac{1}{2} \operatorname{Var}\left(v_{i} \mid x_{1}, \ldots, x_{N}\right)\right\}
$$

Let us denote the marginal mean-vector, variance-covariance matrix of the valuation of bidder $i=1, \ldots, N$ and the signals of all bidders $\left(v_{i},\left(x_{1}, \ldots, x_{N}\right)\right)$ by $\left(u_{i}, \mu^{*^{\prime}}\right)$ and $\Sigma_{i}=\left[\begin{array}{cc}\sigma_{i}^{2} & \sigma_{i}^{*} \\ \sigma_{i}^{*} & \Sigma^{*}\end{array}\right]$ respectively. We can then rewrite the conditional expectation in the exponential term of equation (1) as

$$
E\left(v_{i} \mid \mathbf{x}=\left(x_{1}, \ldots, x_{N}\right)^{\prime}\right)=\left(u_{i}-\mu^{*^{\prime}} \Sigma^{*-1} \sigma_{i}^{*}\right)+x^{\prime} \Sigma^{*-1} \sigma_{i}^{*}
$$

and the conditional variance in the exponential term of equation (1) as

$$
\operatorname{Var}\left(v_{i} \mid x=\left(x_{1}, \ldots, x_{N}\right)^{\prime}\right)=\sigma_{i}^{2}-\sigma_{i}^{*^{\prime}} \Sigma^{*-1} \sigma_{i}^{*}
$$

For round $k$, let us partition the vector of signals $\left(x_{1}, \ldots, x_{N}\right)$ into an $(N-k) \times 1$ vector of signals of bidders that remain active, $x_{r}^{k}$, and a $k \times 1$ vector of signals of bidders that have dropped out, $x_{d}^{k}$ - that is let $x=\left(x_{r}^{k}, x_{d}^{k}\right)$.

Similarly, let us partition the variance-covariance matrix of the signals as $\Sigma^{*-1}=\left[\begin{array}{c}\Sigma_{k, 1}^{*-1} \\ \Sigma_{k, 2}^{*-1}\end{array}\right]$ where $\Sigma_{k, 1}^{*-1}$ is an $(N-k) \times N$ matrix pertaining to the bidders active in round $k$ and $\Sigma_{k, 2}^{*-1}$ a $k \times N$ matrix pertaining to the bidders that have dropped out prior to round $k$.

Substituting expressions (2) and (3) into the equation given by (1), we get

$$
\exp \left\{\left(u_{i}-\mu^{*^{\prime}} \Sigma^{*-1} \sigma_{i}^{*}\right)+\sigma_{i}^{*^{\prime}} \Sigma_{k, 1}^{*-1^{\prime}} x_{r}^{k}+\sigma_{i}^{*^{\prime}} \Sigma_{k, 2}^{*-1^{\prime}} x_{d}^{k}+\frac{1}{2}\left(\sigma_{i}^{2}-\sigma_{i}^{*^{\prime}} \Sigma^{*-1} \sigma_{i}^{*}\right)\right\}
$$

for the $i=1, \ldots, N-k$ bidders still active in round $k$.

Letting $\ln P=p, l_{k}$ be a $k \times 1$ vector of ones, $u_{k}=\left[u_{1}, \ldots, u_{N-k}\right]^{\prime}, \Gamma_{k}=\left[\sigma_{1}^{2}, \ldots, \sigma_{N-k}^{2}\right]^{\prime}$, $\Lambda_{k}=\left[\sigma_{1}^{*}, \ldots, \sigma_{N-k}^{*}\right]^{\prime}$ and logarithmizing both sides, we can write a system of equations analogous to the one given under assumption A2 for the log-normal case as

$$
u_{k}-\Lambda_{k} \Sigma^{*-1} \mu^{*}+\Lambda_{k} \Sigma_{k, 1}^{*-1^{\prime}} x_{r}^{k}+\Lambda_{k} \Sigma_{k, 2}^{*-1^{\prime}} x_{d}^{k}+\frac{1}{2}\left(\Gamma_{k}-\operatorname{diag}\left(\Lambda_{k} \Sigma^{*-1} \Lambda_{k}^{\prime}\right)\right)=p \times l_{k}
$$


From this system of equations we can obtain the set of $(N-k)$ round $k$ log-inverse bid functions by solving for $x_{r}^{k}$, the vector of signals of those bidders that remain active, as

$$
x_{r}^{k}=A^{k} p-D^{k} x_{d}^{k}-C^{k}
$$

where

$$
\begin{aligned}
A^{k} & =\left(\Lambda_{k} \Sigma_{k, 1}^{*-1^{\prime}}\right)^{-1} l_{k} \\
C^{k} & =\frac{1}{2}\left(\Lambda_{k} \Sigma_{k, 1}^{*-1^{\prime}}\right)^{-1}\left(\Gamma_{k}-\operatorname{diag}\left(\Lambda_{k} \Sigma^{*-1} \Lambda_{k}^{\prime}\right)+2 u_{k}-2 \Lambda_{k} \Sigma^{*-1} \mu^{*}\right) \\
D^{k} & =\left(\Lambda_{k} \Sigma_{k, 1}^{*-1^{\prime}}\right)^{-1}\left(\Lambda_{k} \Sigma_{k, 2}^{*-1^{\prime}}\right)
\end{aligned}
$$

For each bidder $i=1, \ldots, N-k$ active in round $k$ this gives the inverse bid function as

$$
x_{i}=\left(b_{i}^{k}\right)^{-1}\left(b_{i}^{k}\left(x_{i} ; x_{d}^{k}\right)\right)=A_{i}^{k} p-D_{i}^{k} x_{d}^{k}-C_{i}^{k}
$$

and consequently, the log-bid function as

$$
\ln \beta_{i}^{k}\left(\exp \left\{x_{i}\right\} ; \Omega_{k}\right)=b_{i}^{k}\left(x_{i} ; x_{d}^{k}\right)=\frac{1}{A_{i}^{k}}\left(x_{r, i}^{k}+D_{i}^{k} x_{d}^{k}+C_{i}^{k}\right)
$$

\subsection{Theoretical Implications of Asymmetric Information}

The asymmetric ascending auction model of Hong and Shum (2003) allows for a wide range of asymmetries among bidders, both in the distributions of the private value components and the precision of each bidder's signal, with the behavioral implication of a difference in a specific parameter being potentially dependent on the others..$^{5}$

In the simplest auction settings, for instance pure independent private value or common value auctions, the consequences of asymmetric information, that is differences in the precision of each bidders signal, have very different implications on the behavior of bidders. I discuss these two extreme cases below.

Independent Private Value Auctions Vickrey (1961) showed that in an English independent private value auction, the bidders' optimal strategies are to truthfully bid their valuation. As the valuation of each bidder is independent of the others, observing someone else's valuation has no impact on the valuation of anyone else with average bids being independent of the number of bidders participating in the auction. However in the model presented in Section 2 , signal precision still matters even when bidder valuations are largely independent, that is, when the dispersion in the common value component $r_{0}^{2}$ is very low; bidders that have more precise signals know their own valuations better than bidders with noisier signals. Put differently, bidders with independent private values but more precise signals draw their private value component from a less dispersed distribution, implying that the valuation of one bidder is unlikely to differ much

\footnotetext{
${ }^{5}$ One way to see if changes to a certain parameter have consistent implications across many different parameter combinations is to simulate all but the parameter of interest and see if changing the parameter of interest for the simulated values gives consistent behavioral implications. This is the approach taken by Dionne et al. (2009) who use the same model and simulate a wide range of parameters from a uniform distribution to derive the potential implications of asymmetric information on bidder behavior in Mauritian slave auctions. Instead of taking their approach, I simulate auction outcomes for the two extreme cases - pure independent private value and pure common value auctions.
} 
from that of another bidder. As a consequence, increasing signal precision has the same effect as lowering dispersion in the private value component. With bids still being independent across bidders, average bids will be independent of the number of bidders in an auction.

\section{INSERT FIGURE 1 ABOUT HERE}

To show the effect of changing signal precision, I simulate 10,000 independent private value auctions for varying degrees of signal precision and varying number of participating bidders. The effect described above can be seen clearly in Panel A of Figure 1 in which we see that although the average bid is largely independent of the number of bidders, the overall level of average bids decreases as signals become more precise. This decrease in average bids occurs because increasing signal precision reduces the possibility of bidders with very high valuations participating in the auction. A further implication of increasing signal precision is that, through its effect on the dispersion of bidder valuations, the overall dispersion of bids will also be lower. That is, bidders with higher signal precision effectively draw valuations from a less dispersed distribution and, as there is a one to one relationship between bids and bidder valuations, in turn lower the dispersion of bids.

Common Value Auctions In common value auctions, in which the value of the object to each bidder is the same across bidders, the information possessed by any of the bidders may significantly influence the beliefs of other bidders. For instance, Milgrom and Weber (1982) show that in first and second price common value sealed bid auctions, bidders need to account for the winner's curse, - the possibility of overpaying by not correctly accounting for the negative news that, by winning, a bidder also realizes that he was the one with the highest estimate. To account for the winner's curse, bidder's should strategically lower, or "shade", their bids, with the degree of shading increasing in the number of bidders. The fact that bidders account for the winner's curse by lowering their bids in this manner, leads the average bid to decrease in the number of bidders (Athey and Haile (2002)). Although the Hong and Shum (2003) model is one of English rather than sealed bid auctions, this implication still holds true for cases in which the common value component is large enough for the winner's curse to become an important consideration for

bidders to take into account. In such cases, the implication of asymmetric information is quite intuitive; the more precise the signals of bidders about the common value component, the lower the chances of overpaying and the less they will have to strategically shade their bids.

Again, to show the effect, I simulate 10,000 independent private value auctions for varying degrees of signal precision and varying number of participating bidders. From Panel B of Figure 1 , we can clearly see that as signal precision increases, the average bids become more and more independent of the number of bidders, converging to a relationship more closely resembling that of the independent private value auction in Panel A of Figure 1. Similar implications for common value auctions have been, found for example, in Hendricks and Porter (1988) who show that in auctions for oil drilling rights, the strategies of more informed firms are independent of less informed firms. Another instance is that of Engelbrechts-Wiggans, Milgrom and Weber (1983) who show that in a simple setting where one bidder is perfectly informed about the common value component and the others aren't, the perfectly informed bidder will behave as though he were in an independent private value auction with the poorly informed bidders bidding according to mixed strategies.

Much like in the independent private values case, asymmetric information has an impact on the dispersion of bids; the better the signals of bidders in common value auctions the closer the bids 
will be to the true common value, reducing the dispersion in bids. Hence, another implication of asymmetric information in common value auctions is that the dispersion of bids for better informed bidders will be lower than that of less informed bidders.

Despite certain similarities, differences in asymmetric information has different implications for bidder behavior in each of the two cases. To summarize the main implications of asymmetries in information between bidders for the independent private value and common value cases;

\section{Behavioral Implications for Independent Private Value Auctions}

1. Average bids fall as signal precision improves

2. Dispersion in bids falls as signal precision improves

\section{Behavioral Implications for Common Value Auctions}

1. Average bids become independent of the number of bidders as signal precision improves

2. Dispersion in bids falls as signal precision improves

Although the implications of asymmetric information are clear for the pure independent or pure common value auctions, the effects may no longer be clear in auctions in which both private and common value components matter to bidders, and do so in a potentially asymmetric way. For instance, if consumers are concerned only with the private value component, then differences in information between consumers and resellers are irrelevant. However, if consumers behave as though there were a common value component to buying a car, then not only does the information of other consumers become important, but also potential differences in the signal precision between consumers and resellers. This is why the possible implications of asymmetries are largely an empirical question depending on whether resellers and consumers differ because of asymmetries in information, type or both. However, we can still use the implications for the two extreme cases to see which of these more closely resembles reality and whether there are indications that there are differences in information between consumers and resellers. In the next section, I will first start by examining whether bidder behavior in car auctions suggests a sizable common value component or whether bids are instead consistent with bidders having largely independent valuations. Thereafter, I examine whether the bidding behavior of consumers and resellers differ and whether this difference is consistent with differences in signal precision between the two types of bidders, as predicted by the model described above.

\section{A First Look at Resellers and Consumers}

In this section, I begin by describing the data used in this study, presenting descriptive statistics of the variables used throughout and thereafter present reduced-form evidence that reseller behavior is consistent with their having more precise signals, being able to appraise the value of the cars they are bidding on better than are consumers. 


\subsection{Data}

Auction Data The car auction data used in this study is collected from a large Swedish auction site, using an automated collection algorithm. The site conducts auctions of, among other things, cars, boats, motorcycles and commercial real estate property. This study focuses solely on the car auctions.

Car auctions on the site are conducted on a weekly basis, with new vehicles being listed throughout the day every Friday and ending on either Tuesday, Wednesday or Thursday the following week. Auctions are conducted sequentially, with a single new auction starting every five minutes from

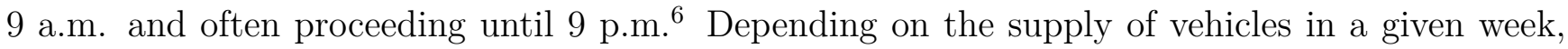
there may be periods when no auctions take place, often lasting no more than a few hours.

Once a car has been listed for auction, anyone is free to follow the bidding process and view the detailed vehicle information without having to register an account. Persons interested in placing a bid have to register an account and are able to place bids, with a minimum incremental bid of 70 USD 7 at no cost 8 If a bidder wants to withdraw a bid, it is possible to do so, although cannot be done by bidders themselves.9 up until six hours before the final countdown (described below) is officially initiated. Should a bidder place the winning bid, the bidder is legally bound to go through with the purchase $\mathrm{1}^{10}$ The history of bids is publicly available, although only the five latest bids are shown, together with the username of the user placing the bid, the time at which the bid was placed as well as the bid itself. Although not obviously available, a self-reported location is also available for each bidder, accessed by moving ones mouse over a specific bidder's username. 11 Once the auction ends, all information regarding the vehicle is removed, including the final five bids.

Every car listed for auction is carefully reviewed by an independent mechanic, ${ }^{12}$ and a summary of the review together with detailed technical information is made available to the public at the start of each auction. The information is provided in a standardized format and can be broadly categorized into technical, legal and qualitative; Technical and legal information is taken from the Swedish Transport Agency's vehicle register, containing information about the bodywork, engine, size as well as the inspection period and tax details. The qualitative information contains the mechanic's assessment of the different parts of the vehicle including an overall vehicle assessment and more detailed assessments of the bodywork, engine, breaks, gearbox and interior. Each vehicle is located at one of roughly 15 locations in Sweden and anyone interested may go and test-drive

\footnotetext{
${ }^{6}$ The sequential nature is such that, depending on popularity, a given auction may not end until the next one begins. This means there are periods when multiple auctions are underway simultaneously.

${ }^{7}$ All values throughout are converted to USD at an exchange rate of 7 SEK/USD.

${ }^{8}$ The site also offers an automated, or proxy, bidding service at no extra cost. Any user interested in using the service, merely states the maximum price he or she is willing to pay and the proxy bidding system automatically places bids until you have either won the auction or the currently highest bid has exceeded your maximum limit. Should the same bid be placed by two users, either automated or human, it is the bid that was placed first that is counted. For a more detailed discussion on the mechanics of proxy bidding see e.g. Bajari \& Hortaçsu (2003).

${ }^{9}$ Instead the user has to contact the auction house directly and ask for the bids to be withdrawn.

${ }^{10}$ This means that should you decide to back out after having won the auction, you will have to pay a fee for that particular auction as well as costs incurred by the seller in putting the vehicle up for auction again. While this means that one does not actually have to purchase the vehicle and incur the entire cost, the cost of compensating the seller for loss of business may still turn out to be significant.

${ }^{11}$ The location data was only noticed late into the data collection process and is available for only a sub-sample of all bidders.

${ }^{12}$ To minimize conflicts of interest, the auction site provides full refunds and the possibility to terminate the transaction if consumers are able to prove serious hidden faults with the help of their own mechanic.
} 
the given vehicle on pre-specified dates. Sometimes pre-specified dates are not given, in which case one has to call and make an appointment.

The exact time at which an auction ends is not known in advance; every vehicle is listed with a so-called "countdown time" at which point a 3-minute timer starts and proceeds to reset until no new bid is placed within a consecutive 3-minute period.13 Once the 3-minute period passes with no new bid being placed, the auction ends and the item is suspended. Every vehicle has a secret reserve price ${ }^{14}$ and if the winning bid is above this reserve price, it is automatically accepted and the winning bid, together with the vehicle name, winner's username, winning bid and ID number of the vehicle, is posted online for 10 days. Should the reserve price not be reached, the seller is free to choose whether to sell the vehicle at the highest bid or to withdraw the item and attempt to resell it at a later date.

A much more thorough description of the vehicle data provided for each auction can be found in the appendix.

Population Data In order to be able to match bidders' self-reported locations with each location's population, population statistics were obtained from Statistics Sweden for 2010.

\subsection{Dropout Bids}

Throughout an auction, the number of unique bids submitted by a single bidder can vary, with some bidders only submitting one bid throughout the entire auction. Other bidders may participate over the space of a number of days, potentially submitting many different bids if the number of competing bids is high.

In this study, I will use the ascending auction model of Hong and Shum (2003), presented in Section 2, to structurally quantify the observed differences in bidding behavior between consumers and resellers. However, one of the underlying assumptions of the model is that as bidders drop out of an auction, the price at which they exit - the dropout bid - is observable to all remaining bidders.

As theoretically studied by Avery (1998), bidders may find it optimal to jump bid, significantly increasing their bid over the previous bid and causing a large gap between the two. By conducting a field experiment, Grether, Porter and Shum (2011) find that bidders jump bid both because time is costly as well as to intimidate other bidders.

If a jump bid is placed however, the dropout bids of several bidders will not be observed, being somewhere in between the last normal bid and the jump bid. To make sure that the bids I use are as close as possible to the true dropout bids, I drop all bids below $25 \%$ of the highest bid assuming these to be noise and completely disregarded by the serious bidders ${ }^{15}$ I also completely drop auctions in which there was a jump between bids of at least $20 \%$ of the highest bid as it would be very difficult to say anything meaningful about the dropout bids of a large number of bidders in such an auction. This initial filtration leaves 9,705 out of a total of 17,133 auctions.

\footnotetext{
${ }^{13}$ This is called a "soft" close in the literature. Online auction house eBay on the other hand has a "hard" close whereby the auction ends at a pre-specified time.

${ }^{14} \mathrm{An}$ item's reserve price is not fully secret as there is a publicly available "Yes/No" indicator which lets bidders know whether the reserve price has been reached or not during the entire auction. Due to data collection issues, I do not observe the reserve price signal in my data.

${ }^{15} \mathrm{I}$ have also used a $15 \%$ cutoff with little change in results.
} 
Furthermore, I drop all auctions in which there was a jump larger than $1 \%$ of the highest bid within the period of the auction in which bidders are most active, after the countdown period has been initiated and 3 minutes of inactivity ends the auction. This is because the activity in this period is so high, a jump bid may not give the bidders time to adequately respond before another bidder has already managed to place a higher bid. Generally, jump bids occur infrequently in the final stages of the auction with bidders preferring to place bids equal to the previous bid plus the minimum allowable increment. Next, I remove all auctions in which a jump bid larger than $1 \%$ of the highest bid comes within an hour after any other bid is placed. This extra time makes sure that all bidders that may have been active up until the jump bid had already reasonably dropped out and that the only bidder affected by the jump is the bidder who placed the bid exactly before the jump took place. In essence, all other bidders had the opportunity to place a bid before the jump occurred but choosing instead not to. After filtering the auctions in these additional ways and removing auctions for which there are missing car characteristics, I am left with a sample of 5,732 out of 17,133 auctions which I will use in my main analysis. 16 Finally, I keep only the the last actively placed bid by any given bidder and assign this to be that bidders dropout bid.

\subsection{Descriptive Statistics}

From Table 1, we see that the main sample of data used in this study is comprised of roughly six thousand car auctions collected from a Swedish online auction house between October 7th 2011 and December 22nd 2012.

\section{INSERT TABLE 1 ABOUT HERE}

The number of unique bids submitted in these auctions is roughly 155,000 with roughly 54,000 of these being dropout bids - the last actively placed bid by a given bidder. All bids were placed by 18,305 unique bidders, with, on average, slightly more than 10 bidders participating per auction. Some auctions were more popular than others, with the most popular having attracted 39 unique bidders and the least popular seeing only a couple of bidders. ${ }^{17}$ Having only one observable bidder does not necessarily imply that the car being auctioned is unattractive. Furthermore, auctions with only a single participating bidder have been excluded from the sample ${ }^{18}$.

The average dropout bid is roughly 13,400 USD, with bidders having bid as low as 121 USD and as high as 77,214 USD. The average winning bid is roughly 16,000 USD whereas the "Mint Condition" value of a car - a site-estimated price of the same vehicle in flawless condition - is just below 21,700 USD. While the gap between the average winning bid and the average "Mint Condition" value may suggest that cars are being sold at a discount, this is not usually the case because the cars sold are rarely above average condition. The sample contains all manner of cars, ranging from older models to newer or more luxurious makes with "Mint Condition" values ranging from 1,143 USD to 92,857 USD. In a few cases high-performance sports cars such as

\footnotetext{
${ }^{16}$ As these auctions are potentially removed in a non-random way, my sample may suffer from selection issues, favoring certain auctions as compared to others. Looking at the characteristics of cars in the remaining sample as compared to the full sample, one does indeed see a difference in the means of many of the characteristics.

${ }^{17}$ On very rare occasions, there have been auctions in which not a single bid was placed. As the model presented in Section 3 requires at least one observable dropout bid to estimate, such auctions have been excluded from the sample.

${ }^{18}$ Furthermore, I exclude auctions with fewer than 3 bidders to avoid large differences between the highest and second highest placed bids.
} 
Ferraris, Maseratis and Lamborghinis have been auctioned during the sample period but as these vehicles differ significantly as compared to the average car, both in terms of characteristics and price, these have been excluded from the sample. The average car is just over 4 years old and has on average driven 64,000 miles during its lifetime. The sample also includes cars that are only a few weeks old and have only have 44 miles registered on the odometer. The average car has 154 horsepower and a total car quality rating of 30 (out of 45) which would indicate an average quality for the car's age on all parts surveyed.

Looking at the participating bidders, we see that over the sample, the average bidder participates in around 8 auctions with the average number of wins being 0.50, suggesting that the majority of bidders walk away from this sample of auctions empty-handed. Not only that, but it suggests that there are a number of bidders that are buying significantly more than one car. The highest number of wins sustained by a single bidder during the period was 144 whereas the bidder that was most active in terms of participation, participated in 1,497 auctions. While I am unable to observe whether a bidder is a reseller or not, bidders that have won more than two auctions are likely to be resellers and will be categorized as such. Only slightly more than 3 percent of all bidders in the sample, or 449 individuals, are resellers.

\subsection{Reduced-form Evidence of Resellers and Informational Asymme- try}

In independent private value auctions, auctions in which each bidder's valuation of the good being auctioned is independent of all other bidders' valuations, learning about other bidder valuations conveys no information. This means, for instance, that learning that a specific car is worth 1000 USD to another bidder is not going to influence how much another bidder is personally willing to pay for it. However, in auctions in which values among bidders are interdependent, learning about another bidder's valuation may convey significant information about the value of the good and cause a bidder to revise the bidder's own valuation of that good. For instance, when competing for the right to drill for oil in a specific geographic location, the valuation of a competing bidder that has already been drilling for oil close to the location being auctioned may reveal the beliefs of that competitor about the amount of oil to be extracted in that particular location (as in e.g. Hendricks and Porter, 1988).

As we have seen in Section 2, if there is a sizable common value component in car auctions, we should observe a negative relationship between bids and the number of bidders. That is, as a bidder you are more likely to overpay when you are facing many competing bidders than when only facing a handful. To reduce the chances of overpaying, the bidders should lower, or "shade" their bids, with the degree of shading increasing in the number of auction participants. However as pointed out in Section 2, the better informed the bidders are of the common value component, the less they will have to shade their bids because they will be less likely to overpay to begin with. 19 A further implication, regardless of whether auctions were largely independent private value or common value auctions, was that the better information of a bidder or group of bidders, the lower the dispersion in that bidder's bids.

\footnotetext{
${ }^{19}$ Despite these predictions, there are a number of studies suggesting that bidders in actual fact fail to account for the winner's curse by not lowering their bids enough, both in real life auctions (e.g. Capen, Clapp and Campbell, 1971) and classroom experiments (e.g. Bazerman and Samuelson, 1983). I discuss this literature further on in the paper.
} 
Average Bids and the Number of Bidders To explore whether car auctions have a common value component and if resellers indeed lower their bids less with each additional auction participant, I use a specification similar to that of Bajari and Hortaçsu (2003) given by

$$
\ln b_{i t}=\alpha+\delta N_{t}+\gamma R_{i}+\lambda N_{t} \times R_{i}+x_{i t}^{\prime} \beta+\epsilon_{i t} \text { for } i=1, \ldots I, \text { and } t=1, \ldots, T
$$

where $\ln b_{i t}$ is the logarithmized dropout bid of bidder $i$ in auction $t, N_{t}$ is the number of bidders in auction $t$ and $R_{i}$ an indicator of whether bidder $i$ is a reseller. Other controls $x_{i t}$ for vehicle characteristics and numerous fixed effects are also included. Based on the predictions of the model presented in Section 2, if the common value component is important, bidders will lower their bids but if resellers have better information than consumers, that they do so less than consumers. Therefore, we may expect to find that $\delta$ is negative and that if resellers have better information, that $\lambda$ is positive.

\section{INSERT TABLE 2 ABOUT HERE}

The results of simple, reduced-form Ordinary Least Squares (OLS) regressions of the number of bidders, the reseller dummy and the interaction between the two on the sample of logarithmized dropout bids ${ }^{20}$ presented in Table 2 suggest that bidders are lowering their bids, with the number of bidders having a negative and statistically significant effect. This suggests further, much like the relationship for the common value auction in Panel B of Figure 1, that the car auctions contain a sizable common value component and bidders are shading their bids to avoid the winner's curse. Bajari and Hortaçsu (2003) find that in eBay coin auctions, average bids decline with the number of bidders, arguing this is consistent with the common value component being important in these auctions.

Very much like in Bajari and Hortaçsu (2003), a concern with the reduced-form specification, is that, not only is the number of bidders an endogenous variable, but that the reseller dummy is too, rendering OLS estimates biased and inconsistent. It is not unlikely that the number of times a given bidder participates is related to that bidder's participation cost; bidders with lower participation costs are more likely to participate more frequently perhaps in the hope of winning their preferred car at a bargain price, whereas a bidder with high participation costs is more likely to participate less and pay a little extra to avoid participating again in the future. Similarly, the number of times a bidder wins is likely driven by the demand of that particular bidder; a private individual will not be looking to buy more than one or two cars whereas a professional reseller or trader is likely to have a much higher demand, potentially leading them to be more aggressive and win more auctions. This is why resellers, being both more likely to participate and to win than regular consumers, may be endogenous.

To account for the potential endogeneity in the number of participating bidders as well as being a reseller, I instrument the endogenous variables in the reduced-form analysis; to instrument for the number of bidders in an auction, I proceed in a manner similar to Bajari and Hortaçsu (2003) who use the auction's reserve price, or minimal accepted bid normalized by the item's book value. As I do not observe the reserve price and, due to data collection issues, do not have access to the public signal of whether the secret reserve price has been surpassed, I instrument using the first

\footnotetext{
${ }^{20}$ Dropout bids are logarithmized to ensure consistency between the reduced-form specifications and the lognormal specification of the Hong and Shum (2003) model. The results remain qualitatively the same if one instead uses "Last Active" bids normalized by "Mint Condition" value.
} 
observed bid in the auction. In some sense, the first bid in the auction becomes an effective public reserve price for potential bidders that have not yet decided to enter the auction. If the smallest placed bid is 10 USD, the effective public reserve price for bidders that are yet undecided, or have only just entered the market, is at least 10 USD. However, if an aggressive bidder decided to place a jump bid at the very start of the auction to say 5000 USD, then the effective reserve price for undecided bidders is instead at least 5000 USD.

To instrument for resellers I use bidders' percentual participation rate of the auctions having occurred to date, with the interaction term between resellers and the number of bidders being instrumented by the product of the two individual instruments.

From Table 2, we see that after instrumenting, both effects persist and are now stronger; average bids decline with the number of bidders participating in the auction. However, we also see that resellers lower their bid less with every new participating bidder; being a reseller has a positive effect on bid shading as measured by the positive and statistically significant interaction term 21

Bidders and the Winner's Curse Although recent studies have found that bidders account for the winner's curse (Hong and Shum (2002), Hong and Shum (2003), Bajari and Hortaçsu (2003)) a large number of studies have found that bidders in general fail to account for the winner's curse and lower their bids less than what theory would prescribe, with a nice summary and examples given in Thaler (1988). Experimental evidence also suggests that bidders fail to account for the winner's curse; Bazerman and Samuelson (1983) auctioned off jars of coins, paperclips and other miscellaneous objects with a value of 8 USD to M.B.A. students, finding that on average, they overpaid for the contents by roughly 2 USD. These results are not unique, with other experiments confirming that participants tend to overbid even in a classroom environment (Bazerman and Samuelson, 1985, Kagel and Levin, 1986, Kagel, Levin and Harstad, 1987 and Dyer, Kagel and Levin, 1987). Interestingly, in their classroom experiment involving both students and experts, Dyer et al. (1987) found that industry experts tended to overbid just as much as the college students.

It may be unsurprising that inexperienced bidders are not perfectly rational, perhaps never before having participated in auctions. The majority of us do not participate in auctions very frequently, much less auctions in which we stand to incur significant losses by overpaying. Frequent auction winners, although having started out inexperienced, are likely to learn to avoid making costly mistakes or run out of money and stop participating. Experimental evidence suggests this is at least partly the case with more experienced bidders learning to account for the winner's curse by lowering, or shading, their bids after having participated in a number of auctions beforehand (e.g. Kagel and Levin, 1986, Weiner, Bazerman and Carroll, 1987, Garvin and Kagel, 1994). Resellers, generally participating and buying more frequently than consumers may have learned to avoid the winner's curse through experience. Furthermore, it is not certain that bidders that at first learn to avoid the winner's curse retain their experience, as in Benkard (2000) who shows that for airplane manufacturing, there seems to be a depreciation in learned knowledge. However, this

\footnotetext{
${ }^{21}$ One concern is that there seasonal patterns present in the number of auctions conducted throughout the year; for instance, there is a trough in the number of auctioned cars towards June and December and peak during March and October. To make sure these patterns aren't driving the results, I also rerun the specifications including month or week fixed effects. Including time fixed effects strengthens the results.
} 
would contradict the findings presented above, that resellers actually lower their bids less rather than more.

Alternatively, it may be the case that the degree to which regular consumers lower their bids is too high to begin with, with these bidders lowering their bids too much. Resellers may have realized at some point that they were lowering their bids too far and instead increase their bids to equilibrium levels. This alternative explanation however contradicts a large body of existing evidence which suggests that the degree of shading is lower, rather than higher, than one would expect (e.g. Capen, Clapp and Campbell, 1971) with bidders tending to suffer the winner's curse.

Dispersion in Reseller Bids If resellers have a better understanding or estimate of the value of cars on which they bid at auction, reseller behavior may be more stable with reseller bids being less dispersed than those of consumers, as suggested by the asymmetric ascending auction model of Hong and Shum (2003) in Section 2. Furthermore, resellers may drop out closer to the value of the common component and further from "Mint Condition" value.

\section{INSERT FIGURE 2 ABOUT HERE}

Plotting dropout bids against a car's "Mint-Condition" value, by comparing Panels A and B of Figure 2, we can see that resellers do indeed seem to have a lower dispersion of dropout bids that do consumers. ${ }^{22}$ Furthermore, resellers are much less likely to go above the "Mint Condition" value, something that would suggest that consumers may on certain occasions pay more for a car than it is worth, paying instead as if it were in better condition than the car being auctioned. Not only that, but there is also an indication that consumers tend to set psychological "dropout" prices - bids above which they no longer proceed, regardless of the "Mint Condition" value of the car.23

\section{INSERT TABLE 3 ABOUT HERE}

If we look at how well technical car characteristics explain reseller vis-a-vis consumer bids, from Table 3 we see that these are better able to explain the variation in reseller bids than in consumer bids. This may further suggest that resellers are better able to value cars by looking at their technical characteristics.

Despite lower dispersion of reseller bids being consistent with their having better information about the cars being auctioned, there are many other possible explanations of why this may be the case. For instance, resellers may have the same information as consumers but have less dispersion in their private value component. This would result in resellers having lower dispersion in their valuations and signals, resulting in a lower dispersion of bids. This is why, although these observations are consistent with resellers having asymmetric information, only once we estimate the structural

\footnotetext{
${ }^{22}$ We can formally test whether this is the case using a variance ratio test. Doing so, we find that the dispersion of reseller bids is indeed significantly lower than that of consumers.

${ }^{23}$ Although not reported, these psychological dropout prices are also observable when plotting logarithmized bids against winning bids and not only against the "Mint Condition" value.
} 
parameters can we disentangle the different asymmetries between resellers and consumers and see whether the data, although showing evidence consistent with resellers having better information than consumers, in actual fact do, or whether this evidence is indicative of asymmetries other than in information.

In the next section, I discuss the identification and estimation of the structural model of Hong and Shum (2003) which I will use in order to quantify the degree to which resellers estimates are better than those of consumers and what the implications are for auction revenues.

\section{Identification and Estimation of Structural Model}

The focus of this study is to determine why resellers seem to lower, or shade, their bids less than do bidders which can be considered to be regular consumers and to quantify the degree of the difference. Intuitively, we may expect resellers to have a better understanding of how others value a certain brand or make of car. Resellers potentially have a better understanding of the car market as they not only directly see what given consumers are looking for in a car but have been doing so for a longer period of time allowing the reseller to gain an understanding of the distribution of tastes. It may also be the case that because resellers participate in and win more auctions, they may even improve their ability to value a given car or at least to adapt to the changing tastes of consumers by observing how they behave in auctions. It has also been suggested in the literature that bidders may get a better understanding of their own valuation as they participate in auctions (as in e.g. Hossain, 2008).

Due to the overall complexity of the model presented in this paper, it is not obvious which parameters should be used to capture the desired effect or how the parameter of interest will affect bidder behavior. The most natural candidate to capture the difference in value assessment between resellers and consumers is the variance of the noise, $s_{i}^{2}$, as opposed to the variance of the private value component $t_{i}^{2}$ or the variance of the common value component $r_{0}^{2}$; the variance of the private value component $t_{i}^{2}$ can be thought of as governing the dispersion of idiosyncratic bidder tastes such as preferences for red over blue cars, something unlikely to be affected by whether a bidder is a consumer or reseller. ${ }^{24}$ The variance of the common value component $r_{0}^{2}$, on the other hand, governs dispersion of what can be thought of as an "intrinsic" car value, such as the remaining life-time usage of the car, something that is unique to a given car and will also not be influenced by the type of an individual bidder. Below I present the parametrization of the model and thereafter how I proceed to estimate the structural parameters.

\subsection{Parametrization}

To parametrize the different model primitives, let us first partition the model parameter vector $\theta$ into vectors of parameters corresponding to each of the five model primitives $\left\{\bar{a}, t^{2}, m, r_{0}^{2}, s^{2}\right\}$ - the mean and variance of the private value component, the mean and variance of the common value component and finally the variance of the noise component;

$$
\theta=\left(\theta_{a}, \theta_{t}, \theta_{m}, \theta_{r}, \theta_{s}\right)
$$

\footnotetext{
${ }^{24}$ As the aim of resellers is to resell a given car to consumers, resellers tastes are likely to be governed by those of the consumers they are trying to sell to and not their own private tastes.
} 
Analogously, partition the vector of explanatory variables, $z_{k}^{t}$, of the bidder having dropped out in round $k$ of auction $t$ as

$$
z_{k}^{t}=\left(z_{k, a}^{t}, z_{k, t}^{t}, z_{k, m}^{t}, z_{k, r}^{t}, z_{k, s}^{t}\right)
$$

To capture the effect of being a reseller vis-a-vis a consumer on the dispersion of an individual bidder's value estimate, or signal $X_{i}$, let the standard deviation of the signal noise of the bidder dropping out in round $k$ in auction $t, s_{k}^{t}$, be an exponential function of a given bidder's type, $\rho_{i},{ }^{25}$

$$
s_{k}^{t}=\exp \left\{\frac{1}{2} \times z_{k, s}^{t} \theta_{s}^{\prime}\right\}
$$

The vector of variables $z_{k, s}^{t}$ contains a constant term and a type variable $\rho$ which will take on the value 1 if the bidder is a reseller and 0 if the bidder is a consumer.

The mean value of the private value component is parametrized linearly as

$$
\bar{a}_{k}^{t}=z_{k, a}^{t} \theta_{a}^{\prime}
$$

Identification of private value components comes from both within auction and inter-auction variation and is identified through bidder specific covariates. If no bidder specific covariates are available, then the two parameters governing the mean private value and the mean common value components, $\bar{a}_{k}^{t}$ and $m^{t}$, are not separately identified $\sqrt{26}$

The vector of variables $z_{k, a}^{t}$ will contain a constant term, as well as the total experience of a given bidder $\xi_{i}$ given by the total number of unique auctions the bidder has participated in during the entire sample period. Bidders' overall experience is included to account, albeit in a reducedform manner, for not being able to observe participation costs or demand of different bidders. It is likely that bidders with very high levels of participation have low participation costs, be it in the form of information acquisition costs or opportunity cost of time, as compared to bidders that participate infrequently ${ }^{27}$ Frequent participants are also more likely to be frequent winners of auctions and although imperfectly, the total experience of a given bidder as measured by the total number of times the given bidder participated or won an auction should help control for these differences across bidders.

Identification of the common value component will come largely from cross-sectional variation in auctions, with the mean value of the common component being parametrized linearly as

$$
\bar{m}^{t}=z_{m}^{t} \theta_{m}^{\prime}
$$

The vector of variables $z_{s, i}^{t}$ is going to contain a constant and the "Mint-Condition" value, the age, odometer reading, horsepower and total quality rating of the car sold in auction $t .28$ If one thinks of the common value component as some average resale price of the car or value of the remaining usage, then the age, odometer and car total quality should capture this component. If a car has low age or odometer reading, then it is likely to have a higher resale value should the

\footnotetext{
${ }^{25}$ The term $\frac{1}{2}$ is added for convenience and disappears once the standard deviation is squared. The exponential form is also used by Hong and Shum (2003) and ensures non-negativity of the standard deviation.

${ }^{26}$ In general, the constant terms in the parametrization of the mean private value and the mean common value components, $\bar{a}_{k}^{t}$ and $m^{t}$, are not separately identified.

${ }^{27}$ In dynamic sequential auction models (e.g. Sailer, 2006), participation costs are positively related to bids i.e. higher participation costs cause more aggressive bidding because the bidder would rather pay a little more in the current auction to avoid participating again in the future.

${ }^{28}$ The constant in the mean of the common value component is not going to be separately identified from the constant in the mean of the private value component.
} 
winner want to resell the car after the auction. If this is the case bidders may bid more aggressively for a car with higher usage potential remaining, knowing such a car may fetch a good price when they try to resell it. Furthermore, I use these three variables together with the horsepower of the car as a parsimonious way of controlling for heterogeneity in the auctioned cars. Finally, I control for the "Mint-Condition" value of the auctioned car in order to capture heterogeneity in brands in a simple and parsimonious way, with more valuable brands having a higher "Mint-Condition" value.

To capture potential differences in the importance of the private and common value components between consumers and resellers, let the variance of the private value component be given as

$$
t=\exp \left\{\frac{1}{2} \times z_{k, t}^{t} \theta_{t}^{\prime}\right\}
$$

where the vector of variables $z_{k, t}^{t}$ is going to contain a constant and the type variable $\rho$. In this case, the type variable will capture any potential differences in the dispersion of the private value component for resellers. If we were to find that resellers have a lower dispersion, it would suggest that they care relatively less about the private value component that do consumers, instead preferring the common value component consistent with their participating in the auction with the aim of reseller the car later on.

Let the remaining variance parameters, $r_{0}^{2}$ be parametrized simply as

$$
r_{0}=\exp \left\{\frac{1}{2} \times \theta_{r}\right\}
$$

that is, let the variance of the common value component be constant. In the next Section, I discuss the estimation of these parameters using simulation methods.

\subsection{Estimation}

The Likelihood Function Although a full derivation of the likelihood function for the observed dropout price vector can be found in Hong and Shum (2003), I present a concise summary below in order to clarify certain restrictions that need to be placed on private signals to ensure consistency with the equilibrium bidding strategies and the observed dropout order.

The log-bidding functions in (8), relate all bidders' signals to their equilibrium dropout prices for each round $k$. In the data we do not observe dropout prices for all bidders in every round, instead observing only the dropout price for bidder $N-k$, the bidder that actually does drop out during that round. ${ }^{29}$ This means that only the equations relating the observed dropout prices to unobserved private signals are used in the likelihood function. Let the bid functions of bidders dropping out in round $k$ be denoted

$$
b_{N-k}^{k}\left(x_{N-k} ; x_{d}^{k}\right)=\frac{1}{A_{N-k}^{k}}\left(x_{N-k}+D_{N-k}^{k} x_{d}^{k}+C_{N-k}^{k}\right) \quad \forall k=1, \ldots, N-2
$$

\footnotetext{
${ }^{29}$ The player that finally drops out during round $k$ will be the player with the lowest dropout price during that specific round.
} 
Letting

$$
\begin{aligned}
\mathcal{F} & =\left(\frac{C_{N}^{0}}{A_{N}^{0}}, \ldots, \frac{C_{2}^{N-2}}{A_{2}^{N-2}}\right)^{\prime} \\
\mathcal{G}_{i} & =(\underbrace{0, \ldots, 0}_{N-i-2}, \frac{1}{A_{N-i}^{i}}, \frac{D_{N-i}^{i}}{A_{N-i}^{i}}) \\
\mathcal{G} & =\left(\mathcal{G}_{0}^{\prime}, \ldots, \mathcal{G}_{N-2}^{\prime}\right)^{\prime}
\end{aligned}
$$

we can write the vector of dropout bids as

$$
\mathcal{P}=\mathcal{G}\left(x_{2}, \ldots, x_{N}\right)^{\prime}+\mathcal{F}
$$

In deriving the likelihood function for the asymmetric ascending English auction, Hong and Shum (2003) point out that one must condition on the observed dropout order of bidders in an asymmetric ascending auction model. This implies a constraint on the log-signals $\left(x_{1}, \ldots, x_{N}\right)$, confining them to some region $\Im_{1}(\theta) \subset R^{N}$. Furthermore, although we observe the identity of the winning bidder, we, unsurprisingly, do not observe the winning bidder's dropout bid. This means we need to put a restriction on the signal of the winning bidder that is consistent with his winning the auction but never revealing his dropout price. This also restricts the signal of the winning bidder to a region $\Im_{2}\left(x_{2}, \ldots, x_{N} ; \theta\right) \subset R^{N}$ that is consistent with bidder 1 having won the auction. In essence, these restrictions ensure that dropout prices are increasing given the model parameters $\theta$.

Let $\operatorname{Pr}\left(\Im_{2}\left(\mathcal{G}^{-1}(\mathcal{P}-\mathcal{F}) ; \theta\right) ; \theta\right)$ denote the probability that the signal of the winning bidder is consistent with bidder 1 having won the auction, that is $x_{1} \in \Im_{2}(\theta)$, conditional on the observed dropout vector $\mathcal{P}$ and let $\operatorname{Pr}\left(\Im_{1}(\theta) ; \theta\right)$ denote the probability that $\left(x_{1}, \ldots, x_{N}\right) \in \Im_{1}(\theta)$.

Defining $\mu_{2}^{*}(\theta)$ as the $N-1$ sub-vector of $\mu^{*}$ and $\Sigma_{2}^{*}(\theta)$ the $(N-1) \times(N-1)$ sub-matrix of $\Sigma^{*}$ corresponding to bidders $2, \ldots, N$, let

$$
\begin{aligned}
\mu_{p}(\theta) & =\mathcal{F}(\theta)+\mathcal{G}(\theta) \mu_{2}^{*}(\theta) \\
\Sigma_{p}(\theta) & =\mathcal{G}(\theta) \Sigma_{2}^{*}(\theta) \mathcal{G}(\theta)^{\prime}
\end{aligned}
$$

The authors show that the likelihood function for a given auction can be written as

$$
L(\mathcal{P} \mid \theta)=\frac{f(\mathcal{P} ; \theta) \operatorname{Pr}\left(\Im_{2}\left(\mathcal{G}^{-1}(\mathcal{P}-\mathcal{F}) ; \theta\right) ; \theta\right)}{\operatorname{Pr}\left(\Im_{1}(\theta) ; \theta\right)}
$$

which resembles a truncated multivariate normal likelihood function, where

$$
f(\mathcal{P} ; \theta)=(2 \pi)^{-(N-1) / 2}\left|\Sigma_{p}(\theta)\right|^{-1 / 2} \exp \left[-\frac{1}{2}\left(\mathcal{P}-\mu_{p}(\theta)\right)^{\prime} \Sigma_{p}^{-1}(\theta) \times\left(\mathcal{P}-\mu_{p}(\theta)\right)\right]
$$

and $f(\cdot ; \theta)$ is an $N-1$-variate normal distribution with mean and variance given by $\mu_{p}(\theta)$ and $\Sigma_{p}(\theta)$ above.

Despite being able to explicitly derive the likelihood function, it is difficult to implement because of the need to calculate the multivariate integral in $\operatorname{Pr}\left(\Im_{1}(\theta) ; \theta\right){ }^{30}$ This is why, I, as well as Hong

\footnotetext{
${ }^{30}$ By Corollary 3 in Hong and Shum (2003) p340, the support of the dropout prices $\mathcal{P}(\theta)$ does not depend on the model parameters $\theta$, thereby not violating regularity conditions necessary for deriving asymptotic normality of the Maximum Likelihood Estimator.
} 
and Shum (2003), use simulation based estimation methods to estimate the asymmetric ascending English auction model. The identification of the model parameters as well as the procedure to estimate these will be discussed in Sections 4 and 5 respectively.

Simulation To estimate the structural model presented in Section 2, I will use the simulation technique also used by Hong and Shum (2003). The technique is based on the simulation methods of Laffont, Ossard and Vuong (1995) whereby the estimator minimizes the nonlinear least squares objective function given by

$$
Q_{T}(\theta)=\frac{1}{T} \sum_{t=1}^{T} \sum_{k=0}^{N_{t}-2}\left(p_{k}^{t}-m_{k}^{t}\left(z_{k}^{t} ; \theta\right)\right)^{2}
$$

where $p_{k}^{t}$ is the $k^{t h}$ dropout price of auction $t=1, \ldots, T$ and $m_{k}^{t}\left(z_{k}^{t} ; \theta\right)$ the corresponding expectation, conditional on a vector of explanatory variables $z_{k}^{t}$.

Due to the complexity of calculating $m_{k}^{t}\left(z_{k}^{t} ; \theta\right)$ it is approximated using simulation by $\tilde{m}_{k}^{t}\left(z_{k}^{t} ; \theta\right)$, giving

$$
Q_{S, T}(\theta)=\frac{1}{T} \sum_{t=1}^{T} \sum_{k=0}^{N_{t}-2}\left(p_{k}^{t}-\tilde{m}_{k}^{t}\left(z_{k}^{t} ; \theta\right)\right)^{2}
$$

where

$$
\tilde{m}_{k}^{t}\left(z_{k}^{t} ; \theta\right)=\frac{\frac{1}{S} \sum_{s=1}^{S} p_{k}^{t}\left(\bar{x}_{s}, z_{k}^{t} ; \theta\right) \mathbf{1}\left(\bar{x}_{s} \in \Im_{1 t}(\theta)\right)}{\frac{1}{S} \sum_{s=1}^{S} \mathbf{1}\left(\bar{x}_{s} \in \Im_{1 t}(\theta)\right)}
$$

and $\bar{x}_{s}=\left(x_{1}, \ldots, x_{N}\right)$ is the vector of signals of the bidders in order of dropping out. This objective function yields a consistent estimate of $\theta$ as $S \rightarrow \infty{ }^{31}$

As the indicator function that the observed signals satisfy the truncation condition induces nonsmoothness into the objective function, Hong and Shum (2003) replace it with an approximation utilizing an independent probit kernel-smoother ${ }^{32}$

$$
\mathbf{1}\left(\bar{x}_{s} \in \Im_{1 t}(\theta)\right) \approx \prod_{k^{\prime}=0}^{N_{t}-2} \prod_{j=1}^{N_{t}-k^{\prime}-1} \Phi\left(\frac{p_{k^{\prime}, j}\left(\bar{x}_{s}, z_{k}^{t} ; \theta\right)-p_{k^{\prime}}\left(\bar{x}_{s}, z_{k}^{t} ; \theta\right)}{h}\right)
$$

The iterated estimation and simulation of $\tilde{m}_{k}^{t}\left(z_{k}^{t} ; \theta\right)$ proceeds as follows;

${ }^{31}$ Although the authors suggest using an adjusted objective function given by

$$
\tilde{Q}_{S, T}(\theta)=\frac{1}{T} \sum_{t=1}^{T} \sum_{k=0}^{N_{t}-2} \tilde{P}_{\Im_{1 t}}(\theta)\left(p_{k}^{t}-\tilde{m}_{k}^{t}\left(z_{k}^{t} ; \theta\right)\right)^{2}
$$

whereby one pre-multiplies the squared deviation term by $\tilde{P}_{\Im_{1 t}}(\theta)$ to correct for the bias stemming from the truncation probability in the denominator of $\tilde{m}_{k}^{t}\left(z_{k}^{t} ; \theta\right)$, I do not do so as I have found it to significantly complicate estimation. If one premultiplies the errors by $\tilde{P}_{\Im_{1 t}}(\theta)$, the objective function has a tendency to go to zero for unreasonable parameter values that push the truncation probability $\tilde{P}_{\Im_{1 t}}(\theta)$ to 0 rather than pushing the error to 0 . If however, this probability is left in the denominator then as it goes to 0 it tends to increase the error, instead pushing the optimizer away from such parameter regions.

${ }^{32}$ I have also used plain indicator functions with little change in the results but with more difficulty in achieving convergence. 
1. For iteration $n$ fix $\theta_{n}$

(a) Simulate dropout prices $\tilde{m}_{k}^{t}\left(z_{k}^{t} ; \theta_{n}\right)$ for each auction $t=1, \ldots, T$ and each round $k=$ $0, \ldots, N-2$ by

i. Drawing an $\left(N^{t} \times 1\right)$ random variable vector $\eta_{s}^{t} \sim N(0,1)$ for each auction $t=$ $1, \ldots, T$ and each simulation draw $s=1, \ldots, S{ }^{33}$

ii. Generating a vector of signals $\mathbf{x}_{s}^{t}$ for each auction $t=1, \ldots, T$ and each simulation draw $s=1, \ldots, S$ by linearly transforming the standard normal vectors as

$$
\mathbf{x}_{s}^{t}=\mu^{t}+\Lambda^{t} \eta_{s}^{t}
$$

where $\boldsymbol{\Sigma}^{t *}=\boldsymbol{\Lambda}^{t} \boldsymbol{\Lambda}^{t \prime}$ is the Cholesky decomposition and both $\mu^{t}$ and $\boldsymbol{\Sigma}^{t *}$ are functions of $\theta_{n}$.

iii. Calculating $p_{k}^{t}\left(\bar{x}_{s}, z_{k}^{t} ; \theta_{n}\right) \mathbf{1}\left(\bar{x}_{s} \in \Im_{1 t}\left(\theta_{n}\right)\right)$ for each auction $t=1, \ldots, T$, each round $k=0, \ldots, N-2$ and each simulation draw $s=1, \ldots, S$.

iv. Calculating $\tilde{m}_{k}^{t}\left(z_{k}^{t} ; \theta_{n}\right)$.

(b) Calculate $Q_{S, T}\left(\theta_{n}\right)$.

2. For iteration $n+1$ fix $\theta_{n+1}$ etc.

The authors show that as $T \rightarrow \infty, S \rightarrow \infty, S / T \rightarrow \infty$ and $h \rightarrow 0$ that the distribution of $\hat{\theta}=\arg \min Q_{S, T}(\theta)$ is given by

$$
\hat{\Sigma}^{-1 / 2} \sqrt{T}\left(\theta-\theta_{0}\right) \rightarrow N(0, I)
$$

where

$$
\hat{\Sigma}=\hat{\mathcal{J}}^{-1} \hat{\mathcal{H}} \hat{\mathcal{J}}^{-1}
$$

and for $\tilde{\zeta}_{k}^{t}\left(z_{k}^{t} ; \theta\right)=p_{k}^{t}-\tilde{m}_{k}^{t}\left(z_{k}^{t} ; \theta\right)$

$$
\hat{\mathcal{J}}=\frac{1}{T} \sum_{t=1}^{T} \sum_{k=0}^{N_{t}-2} \frac{\partial}{\partial \theta}\left(\tilde{\zeta}_{k}^{t}\left(z_{k}^{t} ; \hat{\theta}\right) \frac{\partial \tilde{\zeta}_{k}^{t}\left(z_{k}^{t} ; \hat{\theta}\right)}{\partial \theta}\right)
$$

together with

$$
\hat{\mathcal{H}}=\frac{1}{T} \sum_{t=1}^{T}\left(\left[\sum_{k=0}^{N_{t}-2} \tilde{\zeta}_{k}^{t}\left(z_{k}^{t} ; \hat{\theta}\right) \frac{\partial \tilde{\zeta}_{k}^{t}\left(z_{k}^{t} ; \hat{\theta}\right)}{\partial \theta}\right] \times\left[\sum_{k=0}^{N_{t}-2} \tilde{\zeta}_{k}^{t}\left(z_{k}^{t} ; \hat{\theta}\right) \frac{\partial \tilde{\zeta}_{k}^{t}\left(z_{k}^{t} ; \hat{\theta}\right)}{\partial \theta}\right]\right)
$$

The matrices $\hat{\mathcal{H}}$ and $\hat{\mathcal{J}}$ are evaluated numerically using center-difference approximations. All technical details pertaining to the estimation and simulation, such as the choice of bandwidth parameter $h$ and the number of simulation draws $S$, can be found in the Appendix.

\footnotetext{
${ }^{33}$ Following Hong and Shum (2003), the random variables are drawn only once, at the start of the estimation procedure, and kept fixed for all subsequent iterations of the objective function. This is done to eliminate "chatter" or noise caused by the simulation process itself and to ease numerical convergence (for a discussion see Cameron and Trivedi (2005) p394).
} 


\section{Results}

In this section, I present the estimation results for the model presented in Section 2.

From the reduced-form evidence in Section 3, we saw that although bidders reduce their bids with the number of participating bidders in an auction, resellers reduce their bids less than consumers. To disentangle the different effects which may be driving the reduced-form evidence, I estimate the structural auction model presented in Section 2.

\section{INSERT TABLE 4 ABOUT HERE}

From Table 4, if bidder $i$ is a reseller, a bidder that has won at least two auctions throughout the sample, he has a significantly negative effect on the dispersion of his signal $X_{i}$ as measured by the standard deviation of the noise, $s_{k}^{t}$. Put simply, resellers have more accurate signals or value estimates than do their consumer counterparts. Due to the overall complexity of the model however, it is difficult to fully interpret these results and their implications for bidder behavior.

To overcome this difficulty, let us consider three specific cases looking at how bidding behavior is affected by differences in their signal accuracy and how remaining bidders adjust their bids once a bidder with an accurate signal drops out vis-a-vis a bidder with an inaccurate signal:

Case 1 All else equal, how do the bid functions of two bidders, one a reseller and the other a consumer, differ for some generic auction round $k$ ?

If we plot the log-bid functions for these two bidders given the estimated parameter values, we see from Figure 3 that the more accurate the signal, the closer you are to dropping out once the price reaches the value of your signal 34

\section{INSERT FIGURE 3 ABOUT HERE}

On the other hand, the more inaccurate a bidder's signal, the flatter the line becomes, with an intercept that will depend only on the signals of the other bidders. If your signal is highly inaccurate you will choose to completely disregard your own signal instead making your bid dependent only on your beliefs about the remaining bidders' signals.

Case 2 How will some bidder $i$, that is still active during round $k$, react to the dropping out of a reseller vis-a-vis a consumer in the previous round?

Once a bidder drops out, it is assumed that all remaining bidders are able to invert his dropout bid to learn that bidder's private signal $X$. Not only is it assumed that bid functions are common knowledge, but also the model parameters. While this means that bidders cannot observes all other bidders' levels of experience, and although they may not observe the exact draws from the noise distribution, all bidders would be aware of which bidders have better signals and which would have worse signals as given by the dispersion parameter $s_{k}^{t}$. It is not unreasonable to believe that rational players put more weight on less noisy signals and less weight on more noisy signals when updating their expectations.

\footnotetext{
${ }^{34}$ Mathematically speaking, the slope goes towards one and the intercept goes towards zero, with the log-bid function converging towards $b_{i}^{k}\left(x_{i} ; x_{d}^{k}\right)=x_{i}$
} 


\section{INSERT FIGURE 4 ABOUT HERE}

Again, let us plot log-bid functions for a bidder in round $k-1$ and compare these to the updated log-bid functions of round $k$, given that a bidder with a very accurate signal drops out in round $k-1$ or a bidder with a very inaccurate signal drops out in round $k-1$. Consistent with the previous discussion, the implication of asymmetric signal precision suggests that indeed, the higher the accuracy of the bidder that drops out, the more the remaining bidders adjust their bids, that is the slope of the bid function decreases more for the remaining bidders if a low noise bidder drops out as compared to a high noise bidder, as seen in Figure 4.

As in Hong and Shum (2003), the estimated log-bid functions have decreasing slopes meaning bidders with high initial signals revise their estimates down as more and more information becomes available with bidders dropping out of the auction. This is consistent with bidders lowering their bids to account for the winner's curse and, as pointed out by the authors, this property is characteristic of symmetric ascending auctions.

Including total bidder experience to control for unobserved differences in bidder participation costs or bidder demand has very little effect as total number of participations are statistically significant but economically relatively small.

Case 3 Which of two bidders, the reseller or the consumer, updates their bids the most after a third bidder drops out?

Intuitively, the better a bidder's signal, the more certain that bidder should be about the value of the object being auctioned. In one extreme case, a highly experienced bidder $j$ may know the "exact" value of the vehicle because that bidder may already have found a buyer on the secondary market guaranteeing a price $P^{\prime}$ for that specific vehicle. In this situation, the information contained in the signals of the other bidders will in no way impact the valuation of bidder $j$ because he is happy as long as he wins the vehicle for a price below that of $P^{\prime}$. The other extreme is an inexperienced bidder $i$ with a very noisy signal, that once observing a more precise signal may potentially see a large change in his expectation after realizing his own signal was far too unreasonable.

\section{INSERT FIGURE 5 ABOUT HERE}

Plotted in Figure 5 are the estimated round $k$ log-bid functions of two bidders, identical in every respect except for one bidder is a consumer, while the other is a reseller, together with the corresponding updated round $k+1$ log-bid functions for both bidders. Here, we see that bidder $i$, the consumer with the more noisy signal, will adjust his bid more than bidder $j$, the reseller that has the the less noisy signal. Despite having an accurate but still imperfect signal, the more experienced bidder $j$ will adjust his bids but, due to the higher accuracy of his signal, will do so much less than bidder $i$ who is less experienced and has a noisier signal.

In light of these results, we can now revisit the implications of the reduced-form evidence presented in Section 3; Being more experienced in some sense, resellers seem to have a more accurate signal about the value of the auctioned car and because of this, are less reliant on the private information of other, less experienced bidders such as consumers. Not only does this cause resellers to lower their bids less in order to account for the winner's curse, it also reduces the dispersion in reseller bids as compared to consumers. 
One should also distinguish between the winner's curse and signal precision, as adjustments to bids due to a better signal are not the same as changes in behavior due to accounting for the winner's curse. Firstly, in this model it is not obvious that there is bid shading, or a lowering of bids as new information enters a bidder's information set. Whether bids are adjusted up or down depends on the parameters in the model, with some parameter values allowing for positive, rather than negative adjustments to expectations. In this sense, re-conditioning on an ever expanding information set will drive the winner's curse effects whereas, as we have seen, differences in levels of signal precision change how large these adjustments are going to be. Resellers, although also lowering their bids will do so less than less experienced consumers because the signals they had were better to begin with.

One of the goals of this paper was to quantify the degree to which resellers are better able to estimate the value of the cars they bid on than do regular consumers. Using the structural parameters, we are able to answer this question; the standard deviation of the distribution of noise for a regular consumer is roughly 0.73 while that of a reseller is 0.37 , a difference of roughly $50 \%$. That is, the dispersion of noise for resellers is about half that of consumers.

\section{Sources of Asymmetry}

Despite indicating that resellers are better able to appraise the value of the cars they bid on at auction than are consumers, the results shed little light about the nature of the informational asymmetries. Providing a significant amount of public information about each car, it seems reasonable that the auction site greatly helps reduce asymmetries between consumers and resellers, at least regarding the technical aspects of any given car. With the amount of public information available to all bidders, one can ask oneself why resellers still seem to behave in a way consistent with their having more precise signals than consumers.

One possible explanation is that resellers know the secondary car market, as a whole, better, knowing what price they can get for a specific car. The less uncertainty there is about which price a reseller will get when reselling the car, the less the reseller has to worry about overpaying and the more independent the actions of the reseller become. If indeed it is certainty about the resale price that is the source of asymmetries in information, we may be able to observe differences between resellers that would indicate as such. Using a specification similar to that presented in equation (9), I explore whether resellers' signals are more precise because resellers are better at appraising the resale value of a car, rather than the technical characteristics, by exploring whether differences in resale market competition, knowledge or the popularity of certain car models indicates whether the precision in reseller signals comes from less uncertainty regarding a car's resale price.

Resale Market Competition The more competition resellers face in their local markets, the less certainty there is about a car's resale price. If resellers are located in a small market, the population is unlikely to support a large number of competitors and hence resellers in smaller markets may face lower uncertainty regarding the resale price than they would have done, had competition been more severe.

Although limited, I have data on each bidder's self-reported location. In order to test whether the behavior of resellers located in smaller markets is consistent with their having more precise signals, I match the self-reported location with population statistics from Statistics Sweden and for the sub-sample of reseller bids, regress logarithmized dropout bids on the population of each reseller's location, the number of bidders in the auction and the interaction between the two. The results are presented under Model I in Table 5. 
From Table 5 we see that resellers located in less populated locations do in fact lower their bids less as compared to resellers that are located in highly populated locations. This is consistent with resellers in smaller markets facing less competition, being better able to determine the resale price of a given car.

Resale Market Knowledge Experienced, larger resellers may be more certain about the prices they can get for a given car, having bought and sold cars frequently and being able to observe developments in consumer preferences. Resellers that are inexperienced and relatively small may face more uncertainty about the resale price they get, both because they may not participate in the market frequently enough to know its characteristics and because they may be less well-known in their market, potentially attracting fewer consumers to their dealership. A way to check whether such a difference between resellers exists is to see whether the more cars a reseller purchases, the less his bid is affected by those of other bidders. In line with the predictions of the ascending asymmetric auction model of Hong and Shum (2003) discussed in Section 2.2, if larger, or more experienced, resellers are better able to estimate the resale value of their cars than less experienced resellers, more experience resellers may lower their bids even less to account for the winner's curse than inexperienced resellers.

\section{INSERT TABLE 5 ABOUT HERE}

From Model II Table 5, we see that this is indeed the case; the more auctions resellers win, the less they lower their bids with each additional participating bidder in an auction. This suggests that the larger resellers know the market better than smaller resellers and bid more as if they were well-informed bidders.

Popular Brands and Models Resellers are more likely to focus on popular cars, increasing the chances of both selling the car as well as getting a good price once it is actually sold. One may therefore expect that resellers are more certain about the resale value of the most popular cars and hence behave as though they have even better information with regards to the most popular models than they otherwise would. To see whether this is the case, I regress logarithmized dropout bids on a dummy indicating two of the most popular car models in the sample - the Volvo V70 and Volkswagen Passat, the number of bidders in the auction and the interaction between the two.

\section{INSERT TABLE 6 ABOUT HERE}

From Model I in Table 6, we see that resellers lower their bids for each additional participating bidder but do so less for the two most popular cars. This suggest that resellers face less uncertainty about the future resale price of a car if it is of a very popular model.

Together, this evidence suggests that the source of asymmetries between resellers and consumers, as well as between different resellers, stems from uncertainty in the common, or resale, value of a given car and not its characteristics or quality. However, despite these pieces of evidence being consistent with the idea that resellers in the studied auctions have better information not about a car's technical characteristics but about its resale value, the evidence is by no means conclusive proof. Large resellers may differ among other dimensions from small resellers with large resellers having a more diversified car portfolio and not needing to be as careful about which cars 
they buy. Furthermore, resellers in less populated markets may in fact face more uncertain resale prices because of more uncertain demand than do resellers in more populated areas with lower shading being driven by other unobserved reasons. Despite this, the amount and detail of information publicly available to all bidders suggests that informational asymmetries between consumers and resellers stem from other sources.

\section{Counterfactual Simulations}

Providing Additional Information One of the key assumptions of the ascending auction model presented in Section 3 is that all distributional parameters are observable, that is, although bidders cannot observe exact draws from the noise distribution they do know whether bidder draws from a more or less noisy one. Knowing this, once a bidder drops out and the others are able to learn the exiting bidder's private signal, they can put more weight on signals coming from less noisy distributions when updating their own beliefs.

It is however unclear how this sort of asymmetry in signals affects revenues and whether more informed consumers is preferable from a seller's point of view. That is, what is the effect of the auction house providing additional information to lessen the information asymmetry between consumers and resellers, holding all other differences between the two types constant.

To gain intuition, I simulate revenues for two opposing cases and a varying number of bidders. In the first case, all bidders are consumers and have the estimated signal accuracy of normal consumers, that is inaccurate signals. In the second case, all bidders are consumers but instead have the estimated signal accuracy of resellers, that is accurate signals ${ }^{35}$ The difference between the two scenarios is only in the accuracy of the signal, holding all other differences between consumers and resellers constant. The revenues are simulated for 100,000 auctions using the estimated parameters of Model I of Table 4 with the car characteristics set to the sample averages found in Table 1.

\section{INSERT FIGURE 6 ABOUT HERE}

Looking at simulated revenues in Panel A of Figure 6 we see that, if one could provide consumers with more information, revenues would increase but only after a certain threshold of participating bidders is reached; for auctions with fewer bidders, revenues decrease, whereas for auctions with a large number of bidders revenues tend to increase. For auctions with few bidders the decrease in expected revenue is up to $10 \%$ whereas the increase in revenues is up to $10 \%$ for auctions for in which there are many participating bidders. For the average auction, with eleven participating bidders, the increase in expected revenue is roughly $4 \%$. The increase in expected average bids would suggest that if reserve prices are employed by the auction house, the probability that a given car is sold will also increase to the benefit of both sellers and the auction house.

One reason for this asymmetric effect in expected revenues may be that the fewer bidders there are in the auction, the less information becomes available and the lower the possibility to revise estimates during the course of the auction. If signals are more precise from the beginning it seems that bidders are going to want to pay less than they would with noisier signals but without being compensated by increased competition from other bidders. From Panel B of Figure 6, we see that resellers' signal precision makes consumers' average bids independent of the number of bidders, behaving in a way similar to what we saw in Panel B of Figure 1.

\footnotetext{
${ }^{35}$ If there are an odd number of bidders, I allow there to be one more reseller than consumers. Allowing one more consumer than resellers does not change the results qualitatively.
} 
Even assuming that we knew the average number of bidders in an auction, given the discussion in Section 6, as there is already a significant amount of car information provided by the auction site, it is difficult to think of further ways to reduce asymmetries between consumers and resellers. If it is indeed asymmetries in the knowledge about resale prices driving the estimated difference in signal precision between consumers and resellers, it may be beneficial to provide consumers not only with point estimates about historic resale values, but also intervals so that consumers have information about what could be considered a reasonable price range.

Although unavailable during the sample studied in this paper, the Swedish online auction site later created a sister-site specializing in the valuation of cars, giving consumers a much better estimate of what any given car is worth. Not only does the sister-site allow consumers to value the car in its current state, providing both a reseller estimate as well as a price range within which the consumer can expect to buy a similar car from private individuals, it also allows consumers to estimate future sale prices based on the consumer's own estimated car usage. This information is not provided together with the standardized information available for each auction but must instead be accessed separately by each consumer, should they wish to do so.

The Swedish online auction house is not the only auction house providing estimated sale ranges rather than specific estimated sale prices. Other notable examples include Christie's $\mathrm{s}^{36}$ and Sotheby's, ${ }^{37}$ both of which provide estimated sale ranges for the majority of their auctions. The fact that auction houses provide such information may indicate that they are aware of differences between consumers and resellers that may be participating in their auctions and try to even-out the differences as much as possible in order to maximize revenues.

Subsidizing Consumers and Charging Resellers From Figure 6, we saw that if the auction house could lessen the asymmetry in information between resellers and consumers it would be able to increase both the expected revenue and the probability of sale. However, it is unrealistic to assume that the auction house is able to provide enough information to completely remove the asymmetry in information between consumers and resellers and make the signals of the two types equally precise. This may for instance be due to cost reasons - it may be too costly for the auction house to obtain or verify additional information.

Instead of trying to remove the entire asymmetry in information between consumers and resellers the auction house may instead be able subsidize the consumers while at the same time charging the resellers the same amount. This would effectively transfer some of the rents from resellers to consumers and in doing so lower any informational advantages that the resellers may have 38

To assess the impact of a subsidy provided to the consumers at the expense of resellers, I simulate revenues for 100,000 auctions using modifications of the estimated parameters of Model I of Table 4 with the car characteristics set to the sample averages found in Table 1 and bidders being equally split between resellers and consumers. I simulate revenues for two different levels of subsidies - one in which consumers are subsidized by exactly the amount that resellers are charged as a fee and in the other case where resellers are charged more, with the auction house keeping a fraction of the transfer as additional revenue. To simulate the effects of subsidies to consumers and

\footnotetext{
${ }^{36} \mathrm{http}: / /$ www.christies.com

${ }^{37} \mathrm{http}: / /$ www.sothebys.com

${ }^{38} \mathrm{It}$ is not obvious how such a scheme could practically be implemented. One way could be to charge an additional fee if the car is registered by a company and provide a rebate if it is registered by a private individual. Another alternative could be to charge a special reseller fee payable upon purchase while leaving it free to consumers or providing newly registered private individuals a "sign-up bonus" payable at purchase, equivalent to the reseller registration fee.
} 
fees to resellers, I adjust the private value parameters for consumers and resellers so that average signals are higher by the amount of the subsidy and lower by the amount of the fee respectively, without increasing the dispersion in the signals. 39 The idea is that if the auction house subsidizes an individual it is as if an individuals private value for that car increased by the amount of the subsidy without affecting the common value component 40 That is, inverting the signal of a bidder that receives a subsidy should not provide any additional information about the common value component but because all model parameters are assumed common knowledge bidders would still be able to rationally adjust for any subsidy being given out or fee being charged.

From Figure 7, we see that the result of a subsidy of $5 \%$ of the price of an average car to consumers (roughly 700 USD), while at the same time charging resellers the same as a fee has a non-trivial impact on revenues; for auctions with fewer participants expected auction revenues increase by up to $5 \%$ while for auctions with more participants revenues will decrease as compared to the case when no subsidy/fee structure in place.41 This suggests that subsidizing consumers has an impact in the cases where less information becomes available, that is in auctions with fewer bidders. Furthermore, the subsidy/fee structure will induce an increase in the average bids regardless of the number of bidders participating in an auction. The increase in average bids suggests that if reserve prices are implemented then the probability of a car being sold will increase once again benefiting some sellers and the auction house.

\section{INSERT FIGURE 7 ABOUT HERE}

If we look at the asymmetric case in which consumers receive a subsidy of $5 \%$ of the price of an average car while resellers pay a fee of $7.5 \%$ there appears to be not much difference to the symmetric case described above. Expected revenues are slightly lower than in the symmetric case whereas expected bids are higher, regardless of the number of bidders in the auction. Which type of subsidy, if any, the auction house may choose to implement will depend on the overall objective function of the auction house as well as how such structures may affect the equilibrium participation of bidders.

Allowing Consumers into All-Reseller Auctions In the U.S. there are a number of large scale reseller-only car auctions. To participate in such auctions one has to be a registered reseller and private individuals are often not allowed to participate. It is of interest to assess how the auction outcomes would change if consumers were allowed into reseller-only car auctions. Although this would likely be detrimental to resellers, it may be beneficial to the auction house if it can increase the number of auctions it successfully conducts. It may also be beneficial to the consumers as they may be able to buy the same car that they would buy from a reseller but at a potentially lower price and lower risk than buying through classified advertisements.

\footnotetext{
${ }^{39}$ To do this, I increase the mean parameter of the lognormal distribution and decrease the sigma so that the mean of the signal increases while the overall variance remains the same.

${ }^{40}$ It may be the case that subsidizing certain bidders in an auction also affects the common value component, for instance if there is resale after the auction to the same individuals. That is, subsidizing certain bidders may increase their valuation in the resale round and by doing so increase the common value component of the first round. In the auctions I study this is unlikely to be the case as there have been no cars resold through the same auction house and one cannot freely obtain the names or details of all other users participating in any given auction for the purposes of resale at a later stage.

${ }^{41}$ The jaggedness of the expected bids are due to the fact that in auctions with an odd number of participants there is one less reseller whereas in even auctions there are as many resellers as consumers.
} 
To assess the impact of allowing consumers to participate in reseller-only auctions, I simulate revenues for three cases; firstly, I simulate revenues under the assumption that the auction is a reseller-only auction and consumers are not allowed to participate. Secondly, I simulate a case in which there are as many resellers as there are consumers and thirdly, I simulate a case where all resellers have been crowded out and no longer wish to participate at all. As before, I simulate revenues for 100,000 auctions using the estimated parameters of Model I of Table 4 with the car characteristics set to the sample averages found in Table 1.

\section{INSERT FIGURE 8 ABOUT HERE}

From Figure 8, we see that if consumers are allowed into reseller only auctions, and if this leads to an increase in average number of bidders in the auctions, this would be beneficial to the sellers and the auction house; expected revenues would increase due to the increase in competition among participating bidders together with an increase in the size of the average bids. However, the risk associated with opening up to consumers is that, for one reason or another, they crowd out resellers. If opening up to consumers would not increase the expected number of bidders but instead change the composition of the bidders, this would be detrimental to expected revenue. This is due to the fact that resellers not only have more precise signals but generally appear to be more aggressive. Therefore, if consumers crowd out resellers, the number of aggressive resellers goes down, instead being replaced by less aggressive and less informed consumers.

In the end, one of the questions that I am unable to answer is what would be the equilibrium number of resellers and consumers in a marketplace in which there were only resellers but into which one freely allowed consumers to participate. By allowing consumers, you are increasing the number of potential auction participants and therefore competition among bidders. However, this increased competition may lower the number of resellers that find it profitable to participate. Therefore, although the number of average participants increases it is difficult to say by how much the number would increase and what would be the equilibrium number of resellers relative to consumers.

\section{Robustness Checks}

In this section I present the results of various robustness checks to make sure the main results aren't driven by how the sample of auctions is selected or differences in bidders' financial constraints, outside options or participation costs.

Dropout Bid Filtration In order to estimate the structural model presented in Section 2, one needs to observe bidder dropout bids - the price above which the bidder no longer wishes to actively participate in the auction. As I do not necessarily observe dropout bids by looking at the bid history within my data sample, as described in Section 3, I dropped auctions in which there were jump bids in order to be as certain as possible that the bids used in this study correspond to bidder dropout bids. However, the procedure by which I chose which auctions to drop from the sample may have been non-random, favoring certain auctions above others. To make sure such non-randomness in the selection of the sample are not driving the results, I estimate the structural model using the sample which excludes only the auctions with the largest jump bids. From the Model II column of Table 4, we see that the results although quantitatively different from the main specification under Model I in the same table, are qualitatively very similar. One can still see that 
being a reseller reduces a bidder's signal dispersion, suggesting resellers are better able to appraise the value of cars they are bidding on compared to consumers.

Financial Constraints There are a number of different reasons why resellers may shade less than do regular consumers; perhaps resellers are less financially constrained, allowing them to be less careful with their money, choosing instead to be more aggressive. Despite not being able to observe the degree to which different bidders are financially constrained, I try to measure the degree of financial constraints by using both the total number of auctions a bidder has won as well as the highest bid the bidder has placed throughout the sample. Firstly, the number of total auctions a bidder has won may in some sense capture the difference in the financial capacity of different resellers with resellers that purchase more frequently being less likely to be financially constrained than those resellers that purchase less frequently. Secondly, looking at the number of auctions a bidder has won would not help capture the financial constraints of non-resellers, that is bidders winning at most two auctions, so to try to capture the financial constraints of consumers, I use the highest bid a bidder has placed in any auction. The highest placed bid may not necessarily be a winning bid but will give an indication of how much the bidder was potentially able to pay for a car.

\section{INSERT TABLE 7 ABOUT HERE}

Even after attempting to account for differences in financial constraints between different bidders, we see from Model I in Table 7 that resellers still shade more than non-resellers. The effect remains statistically significant although does fall in magnitude from 0.05 in the main specification of Model II in Table 2 to 0.036 when looking at the coefficients of the IV specifications. This suggests that resellers are less financially constrained and that this may affect the degree to which they shade but that differences in financial constraints aren't able to fully explain the effect.

Participation Costs and Outside Options An alternative reason why resellers may shade less is because they have a greater ability to wait for a good deal than consumers. This may for example be because resellers have lower participation costs than do regular consumers. A normal consumer has to take time out of his regular schedule in order to not only find an auction he is willing to participate in but also to take the time to place bids and follow the bidding process. A very busy consumer may be less willing to spend time looking for bargains simply because the consumer doesn't have a lot of time to allocate to the task of participating in car auctions or because that consumer's time in very valuable. Furthermore, resellers are unlikely to care about specific features of a car focusing instead on brands and models that are easier to resell whereas consumers may focus on details catering to their specific needs at the time of purchase. This means that cars may be a lot more homogenous in the eyes of a reseller than in the eyes of a consumer, with the consumer valuing a given set of characteristics more than a reseller. In both of these cases, consumers may, on a whole, value a given car more than resellers making shading more necessary in order not to overpay.

Again, I observe neither the participation cost nor the outside options of different bidders. In order to try to capture these two effects, I include controls for the total number of auctions a given bidder has participated in during the sample period as well as the number of identical car models that still remain to be sold a given week. The total number of auctions a given bidder has participated in is intended to capture differences in participation costs, with more frequent participants likely to have lower participation costs. The number of cars of an identical model 
that are still available during a given week, on the other hand, is intended to capture the value of the outside option - the more cars of an identical brand and model that remain, the better your outside option and the less aggressive you have to be in order to win a specific car.

From Model II in Table 7 we see that bidders that are frequent participants bid less than do infrequent participants, indicating that more frequent participants have lower participation costs and because of this bid less aggressively. Further we see that the fewer auctions of similar models, the more bidders are willing to bid on average, in line with a decline in the value of the outside option. Despite these two effects, we still see that resellers shade less than do non-resellers but with an effect slightly lower than in the baseline IV specification.

Time to Countdown as an Additional Instrument As mentioned previously, the auction house does not set a fixed time for the end of any given auction. Instead, at a specific, predetermined and public time a timer starts. If no new bids are placed within a consecutive 5 minute period, the auction ends. Therefore, there is an element of randomness to when the auction ends. However, as all cars are listed on Fridays, throughout the day, certain cars will be on auction for more days than others. For instance a car with a countdown timer start on Tuesday will be online for roughly 4 days whereas one with a countdown timer start on Thursday will be online for an additional 2 days. This difference in the number of days for which a car will potentially lead to an exogenously different number of bidders being able to enter into an auction, simply because there is more time for potential bidders to arrive. Therefore, I use the time between listing and the start of the countdown timer as an additional instrument for the number of bidders in an auction.

\section{INSERT TABLE 8 ABOUT HERE}

The results are presented in Model I of Table 8 and are very similar in magnitude to the OLS results of Model II in Table 2. The number of bidders still has the expected negative sign and is statistically significant at a $1 \%$ significance level but the interaction term is no longer statistically significant. The first stage F-statistics in all cases are much lower than in the main regressions suggesting the instrument may be quite weak. Although the interaction term is insignificant, the signs and magnitudes are similar to the OLS results and the results which use the minimum bid as an instrument.

Grouping Bidders As an additional robustness check, I divide the total number of participating bidders in an auction into the number of consumers and the number of resellers, and add these separately into the regressions discussed in Section 3. The previous results suggest that increasing the number of consumers in an auction should have a negative effect on expected bids as they need to shade their bids in order to avoid the winner's curse. However, adding additional resellers should should not have such a large negative impact as they have more precise signals and do not shade their bid as much. From Model II of Table 8 we see that this is indeed the case; an additional reseller, although decreasing the average bid does so much less than an additional consumer. I also test whether the parameters are identical and can reject the null hypothesis that the parameters are identical at a $1 \%$ significance level.

\section{Conclusion}

In his influential paper, Akerlof (1970) showed that in used car markets in which informational asymmetries exist between the sellers and buyers of cars, markets may not work efficiently as 
consumer behavior takes into account the possibility of purchasing a poor quality car - a "lemon". Car auctions, in which consumers may be competing for cars against professional resellers, similar asymmetries may exist; resellers may not only be more mechanically savvy, they may know the resale market and what a given car is actually worth while consumers may be unable to distinguish "lemons" from good quality cars and may be unaware of how what the value of a given car in its given state actually is. Should such differences in information exist, it may influence the bidding behavior of the two very different types of bidders, inducing a more careful behavior of poorly informed bidders. In this paper, I study whether the bidding behavior of resellers is consistent with their being able to appraise the value of the cars they are bidding on better than are consumers.

Auctions can simplistically be divided into two paradigms - the independent private value auction in which bidders' valuations are only known to the bidders themselves and do not depend on how other bidders value the object, and the common value auction. In common value auctions, the object being auctioned has the same value to all participants, although no bidder truly knows what that value is. Instead, bidders rely on private estimates, or signals, to guide their bidding. How precise these signals will likely affect not only a given bidder's behavior but also the behavior of those bidders around him. To understand how bidder behavior changes with more precise signals about the value of an auctioned car, I use the asymmetric ascending auction model of Hong and Shum (2003).

Due to its generality, the theoretical model predictions may differ for different parameter values. Even in the simplest auction scenarios, a pure independent private value or a pure common value auctions, differences in asymmetric information among bidders have different implications on their behavior. In auctions in which the independent private value component is of most importance, a better signal causes average bids to decline irrespective of the number of bidders participating in the auction. However, in auctions in which it is the common value component that is of most importance, a more precise signals makes bidders more confident about the value of the auctioned object. Because of this confidence, average bids will decline less than they otherwise would have done due to bidders accounting for the winner's curse - the possibility of overpaying by not accounting for the fact that the winner likely had the most optimistic signal - by "shading" or lower their bids. That is, as bidders' signals become more precise in a common value setting, they no longer have to account for the winner's curse as much, resulting in average bids that no longer depend on the number competing number of bidders one faces in an auction.

In this paper, I start by presenting reduced-form evidence from a unique data set of roughly six thousand online car auctions carried out in Sweden that, bidders that are likely to be car resellers lower, or shade, their bids less than bidders that have won only one, or at most two, auctions. I argue that, consistent with the predictions of the theoretical model, this effect is not driven by differences in participation costs, outside options or financial constraints of resellers and consumers but instead that resellers shade less because they are better able to estimate the value of the cars which they are bidding on. Furthermore, I try to quantify the extent to which resellers shade less than do consumers by estimating the asymmetric ascending auction model of Hong and Shum (2003), and find that through their experience, resellers' signals are somewhat more accurate than that of consumers. I find that the standard deviation of the noise distribution of resellers is roughly half that of consumers. In other words, resellers are better able to estimate the value of the auctioned cars and become less reliant on the estimates of others. Because of this, the more resellers do not need to adjust their beliefs as much during the course of the auctions and as a consequence lower their bids less as new information becomes available. I also show that as a consequence of asymmetries in signal precision, when a bidder with an accurate signal drops out, the remaining bidders adjust their beliefs more than when a bidder with an inaccurate signal 
drops out. Bidders do not treat all information equally, with more accurate public information being more important than less accurate information.

Using the estimated model parameters, I simulate three different auction outcomes - one in which the auction house is able to provide more information to the consumers and is therefore able to increase their signal precision, one in which consumers are subsidized at the expense of resellers and one in which consumers are allowed into all-reseller auctions. I find that providing consumers with more information would increase expected auction revenues and expected bids. Further, I find that subsidizing consumers would increase auction revenues for auctions with relatively fewer participants but would increase expected bids for all auctions, regardless of the number of participating bidders. Finally, the estimated model parameters suggest that allowing consumers into all-reseller auctions would increase revenues only in the case when this leads to an increase in the average number of participating bidders in an auction. If consumers only replace existing resellers this will have a detrimental effect on revenues because resellers appear to be a more aggressive type of bidder than are consumers.

Having not only argued that resellers do in actual fact have more precise signals than do consumers, I also argue that because the online auction house from which the studied data is taken provides a very detailed mechanical assessment of each auctioned car, differences in assessing car quality are unlikely to be the source of the asymmetries in signal precision between resellers and consumers. By showing that large resellers seem to have better information than small resellers, and that resellers in general have more precise signals about more popular cars, I argue instead that resellers know the resale, or common component, value better than do consumers, understanding the price a given car can fetch on the secondary market. 


\section{References}

[1] Akerlof, G. A. (1970), The Market for "Lemons": Quality Uncertainty and the Market Mechanism. The Quarterly Journal of Economics, Vol 84, No. 3, 488-500

[2] Avery, C. (1998), Strategic Jump Bidding in English Auctions. The Review of Economic Studies, Vol 65, No. 2, 185-210.

[3] Athey, S. and P. A. Haile (2002), Identification of Standard Auction Models. Econometrica, Vol. 70, No. 6, 2107-2140.

[4] Bajari, P. and A. Hortaçsu (2003), The Winner's Curse, Reserve Prices and Endogenous Entry: Empirical Insights from eBay Auctions. RAND Journal of Economics, Vol 34, No. 2, 329-355.

[5] Bazerman, M. H. and W. F. Samuelson (1983), I Won the Auction but don't want the Prize. Journal of Conflict Resolution, Vol 27, No. 4, 618-634.

[6] Bazerman, M. H. and W. F. Samuelson (1985), The Winner's Curse in Bilateral Negotiations. Research in Experimental Economics, Vol 3, 105-137.

[7] Benkard, C. L. (2000), Learning and Forgetting: The Dynamics of Commercial Aircraft Production. American Economic Review, Vol 90, No. 4, 1034-1054.

[8] Cameron, A. C. and P. K. Trivedi (2005), Microeconometrics: Methods and Applications. Cambridge University Press.

[9] Capen, E. C., R.V. Clapp and W. M. Campbell (1971), Competitive Bidding in High-Risk Situations. Journal of Petroleum Technology, Vol 23, No. 6, 641-653.

[10] Cassing, J. and R. W. Douglas (1980), Implications of the Auction Mechanism in Baseball's Free-Agent Draft. Southern Economic Journal, Vol 47, No. 1, 110-121.

[11] Dessauer, J. P. (1981), Book Publishing. New York: Bowker.

[12] Dionne, G., P. St-Amour and D. Vencatachellum (2009), Asymmetric Information and Adverse Selection in Mauritian Slave Auctions. The Review of Economic Studies, Vol 76, No. 4, 12691295.

[13] Dyer, D., J. H. Kagel and D. Levin (1987), The Winner's Curse in Low-Price Auctions. Working Paper, University of Houston.

[14] Engelbrecht-Wiggans, R., P. Milgrom and R. Weber (1983), Competitive bidding and proprietary information. Journal of Mathematical Economics, Vol 11, No. 2, 161-169.

[15] Garvin, S. and J. H. Kagel (1994), Learning in common value auctions: Some Initial Observations. Journal of Economic Behavior and Organization, Vol. 25, 351-372.

[16] Grether, D., D. Porter and M. Shum (2011), Intimidation or Impatience? Jump Bidding in On-line Ascending Automobile Auctions. Working Paper, Chapman University.

[17] Haile, P. (2001), Auctions with Resale Markets: An Application to U.S. Forest Service Timber Sales. American Economic Review, Vol 91, No. 3, 399-427. 
[18] Hendricks, K. and R. H. Porter (1988), An Empirical Study of an Auction with Asymmetric Information. American Economic Review, Vol 78, No. 5, 865-883.

[19] Hendricks, K., R. H. Porter and C. Wilson (1994), Auctions for Oil and Gas Leases with an Informed Bidder and a Random Reservation Price. Econometrica, Vol 62, No. 6, 1415-1444.

[20] Hong, H. and M. Shum (2002), Increasing Competition and the Winner's Curse: Evidence from Procurement. The Review of Economic Studies, Vol 69, No. 4, 871-898.

[21] Hong, H. and M. Shum (2003), Econometric Models of Asymmetric Ascending Auctions. Journal of Econometrics, Vol 112, No. 2, 327-358.

[22] Hossain, T. (2008), Learning by Bidding. RAND Journal of Economics, Vol 39, No. 2, 509-529.

[23] Kagel, J. H. and D. Levin (1986), The Winner's Curse and Public Information in Common Value Auctions. American Economic Review, Vol 76, No. 5, 894-920.

[24] Kagel, J. H., D. Levin and R.M. Harstad (1987), Judgement, Evaluation and Information Procession in Second-Price Common Value Auctions. Working Paper, University of Houston.

[25] Laffont, J. J., H. Ossard and Q. Vuong (1995), Econometrics of First-Price Auctions. Econometrica, Vol 63, No. 4, 953-980.

[26] Lewis, G., (2011), Asymmetric Information, Adverse Selection and Online Disclosure: The Case of eBay Motors. American Economic Review, Vol 101, No. 4, 1535-1546.

[27] Milgrom, P. and R. J. Weber (1982), A Theory of Competitive Bidding. Econometrica, Vol 50, No. 5, 1089-1122.

[28] Roll, R. (1986), The Hubris Hypothesis of Corporate Takeovers. Journal of Business, Vol 59, No.2, 197-216.

[29] Roth, A. E. and A. Ockenfels (2002), Last-Minute Bidding and the Rules for Ending SecondPrice Auctions: Evidence from eBay and Amazon Auctions on the Internet. American Economic Review, Vol 92, No. 4, 1093-1103.

[30] Sailer, K. (2006), Searching the eBay Marketplace. Working Paper, University of Munich.

[31] Tadelis, S. and F. Zettelmeyer (2011), Information Disclosure as a Matching Mechanism: Theory and Evidence from a Field Experiment. Working Paper, Northwestern University.

[32] Thaler, R. H. (1988), Anomalies: The Winner's Curse. Journal of Economic Perspectives, Vol 2, No. 1, 191-202.

[33] Vickrey W. (1961), Counterspeculation, Auctions, And Competitive Sealed Tenders. Journal of Finance, Vol 16, No. 1, 8-37.

[34] Weiner, S., M. H. Bazerman and J. Carroll (1987), An Evaluation of Learning in the Bilateral Winner's Curse. Working Paper, Northwestern University. 


\section{Appendix}

\section{Estimation details}

Optimizer Starting Values, $\theta_{0}$ For estimation of the full model, starting values are chosen by first estimating the model using a vector of zeros as starting values with one simulation draw and thereafter setting the estimated variance parameters to zero. Using these new starting values, I estimate the model using 50 simulation draws. Although estimation does not seem to be sensitive to the initial starting parameters, picking sensible parameters from the beginning greatly improves convergence and estimation time.

Optimizer I have used three different optimizers in estimating the model; Firstly, I have used the Knitro 7 optimizer in Matlab with function and parameter tolerances set to 10e-12. Secondly, as the main optimizer, I use Matlab's built-in Fminunc optimizer using automated settings with function and parameter tolerances set to 10e-12. ${ }^{42}$ Thirdly, to find the starting values I have used Matlab's Fminsearch with function and parameter tolerances set to 10e-12, which performs very well when compared to the others if using a vector of zeros as initial starting values. Although Knitro 7 is more stable and efficient, both Knitro and Fminunc optimizers produce very similar parameter estimates.

Parallelization The nature of the optimization problem easily allows for parallel computing along one of two dimension; one can parallelize across auctions or one can parallelize across simulated draws. I parallelize across auctions, that is, each core independently calculates a predicted dropout price vector $\tilde{\mathcal{P}}^{t}$ for a given auction $t$. Alternatively one can parallelize across each independent simulation draw $s$, whereby one core draws a singal draw $s$ and calculates thet predicted dropout price vector $\tilde{\mathcal{P}}_{s}^{t}$ for that given simulation. The choice between these two alternative ways of paralellizing the computation depends largely on the number of auctions $T$ and the number of simulation draws $S 43$

Bandwidth of Probit Kernel Smoother, $h \quad$ I choose $h=0.01$ as in Hong and Shum (2003). Unlike the authors however, I find that changing the bandwidth to a lower number to have very little difference on the resulting parameter estimates while increasing it to $h=0.1$ affects both convergence and parameter results. Although convergence becomes faster, the estimated parameter values start becoming unstable.

Approximation Step, $\delta$ The differencing approximation step $\delta$ is set to $\delta=0.0001$ The derivatives used in calculating the estimated parameters' standard errors are approximated using center differencing approximations;

\footnotetext{
${ }^{42}$ I also replace all basic Matlab functions with optimized and improved versions found in the freely available Lightspeed Toolbox by Microsoft Research.

${ }^{43}$ Due to the recursive nature of the model, parameter estimation becomes a time-consuming process. I believe that if one wishes to estimate either a more complex model than the one presented in this study, be it in terms of the number of observations, simulations or explanatory variables, one will most likely need to resort to cluster computing to keep estimation times reasonable.

${ }^{44}$ This value of the approximation step gives the most conservative standard errors. Due to the number of individual approximations that need to be made in order to calculate the standard errors, the results are quite sensitive to large changes in $\delta$, where "large" is a hundred-fold or higher decrease in the step.
} 


$$
\begin{gathered}
\frac{\partial f(x)}{\partial x} \approx \frac{f(x+\delta)-f(x-\delta)}{2 \delta} \\
\frac{\partial^{2} f(x)}{\partial x^{2}} \approx \frac{f(x+\delta)+f(x-\delta)-2 f(x)}{\delta^{2}} \\
\frac{\partial^{2} f(x, y)}{\partial x \partial y} \approx \frac{f(x+\delta, y+\delta)-f(x+\delta, y-\delta)-f(x-\delta, y+\delta)+f(x-\delta, y-\delta)}{4 \delta^{2}}
\end{gathered}
$$

Simulation Draws, $S$ The number of simulation draws $S$ is set to 50 . At this time, this is the maximum number of draws that gives reasonable estimation times together with a sample of five to ten thousand auctions. I have also tried using more simulations for smaller samples and find that although there is a difference, the results remain both qualitatively and quantitatively similar. 


\section{Tables and Figures}

\begin{tabular}{l|cccc} 
Sample Variables & \multicolumn{3}{c}{ Oct. 7th 2011 } & Dec. 22nd 2012 \\
\hline \hline Sample Period & Full & 154,637 & Dropout & 53,751 \\
Nr. Bids & & & & \\
& Mean & Std. & Min. & Max. \\
Auction Variables & 10.35 & 4.62 & $3 \$$ & 39 \\
\hline \hline Nr. Bidders (per Auction) & 13,425 & 8,092 & 121 & 77,214 \\
Droupout Bids (USD) & 15,998 & 8,582 & 407 & 77,214 \\
Winning Bid (USD) & 0.50 & 2.71 & 0 & 144 \\
Nr. Bidder Wins & 8.54 & 33.17 & 1 & 1,497 \\
Nr. Bidder Participations & 0.03 & 0.15 & 0 & 1 \\
Reseller & 5,732 & - & - & - \\
Nr. of Auctions & 18,305 & - & - & - \\
Nr. Unique Bidders & & & & 37 \\
& & & & \\
Car Variables & Mean & Std. & Min. & Max. \\
\hline \hline Age (Years) & 4.17 & 2.31 & 0.04 & 46.87 \\
Odometer (Miles) & 64,140 & 37,180 & 44 & 791,869 \\
Horse Power & 154 & 47 & 54 & 514 \\
Total Rating & 30 & 2.8 & 9 & 92,857 \\
"Mint Condition" Value (USD) $\$$ & 21,674 & 9,800 & 1,143 & \\
\hline \hline
\end{tabular}

Table 1: §Sample consists of auctions with at least 3 active bidders. §§"Mint Condition" value given is that of an identical vehicle in brand new condition, as opposed to the replacement cost or estimated auction price. Descriptive statistics for key variables, pertaining to roughly six thousand ascending online car auctions carried out by Swedish online auction house. 


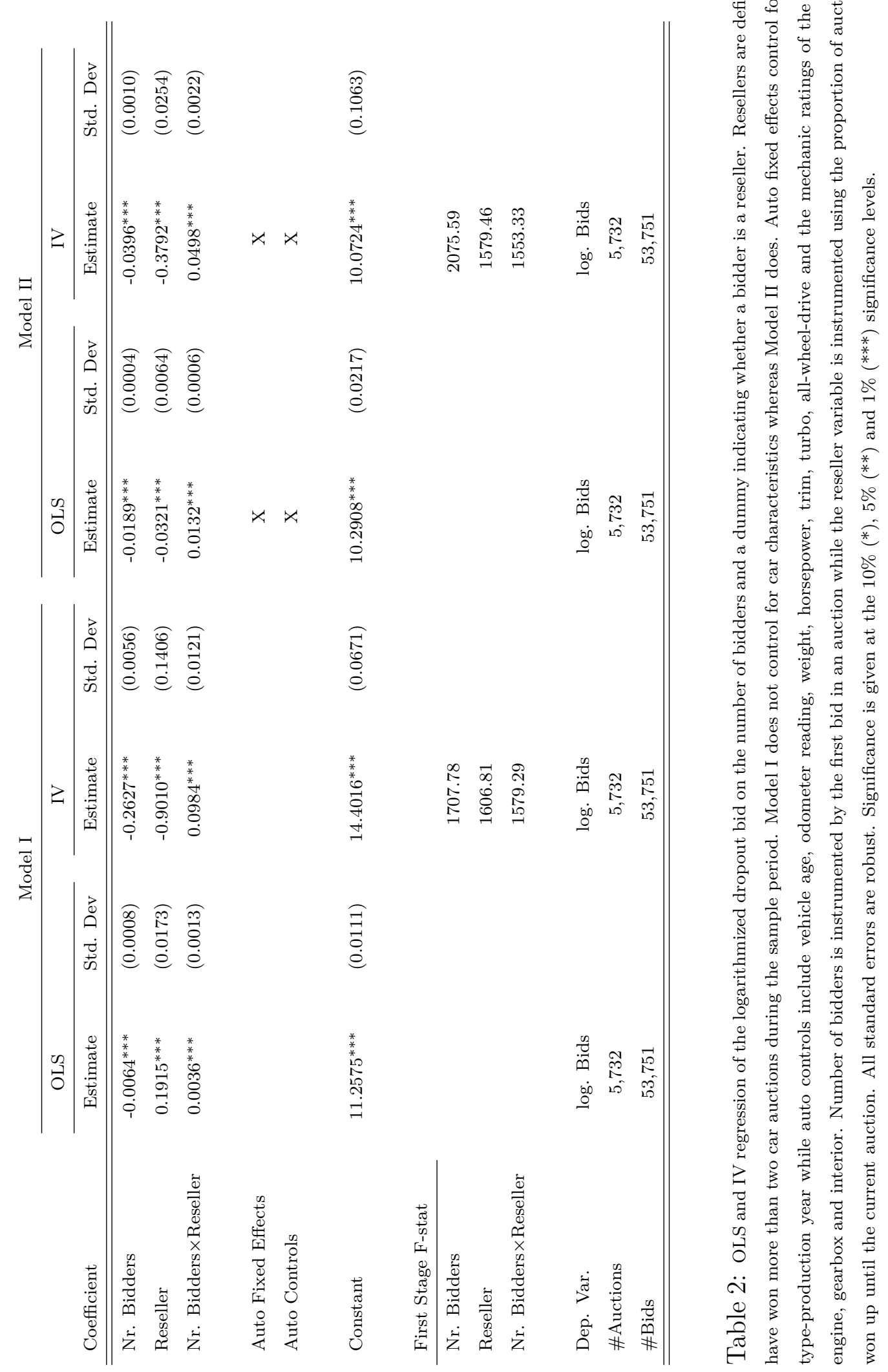




\begin{tabular}{|c|c|c|c|c|}
\hline \multirow[b]{3}{*}{ Coefficient } & \multicolumn{2}{|c|}{ Model I } & \multicolumn{2}{|c|}{ Model II } \\
\hline & OLS & & OLS & \\
\hline & Estimate & Std. Dev & Estimate & Std. Dev \\
\hline Auto Fixed Effects & $\mathrm{X}$ & & $\mathrm{X}$ & \\
\hline Auto Controls & $\mathrm{X}$ & & $\mathrm{X}$ & \\
\hline Constant & $8.0429^{* * *}$ & $(0.1682)$ & $10.3069^{* * *}$ & $(0.1628)$ \\
\hline R-square & 0.9025 & & 0.8506 & \\
\hline Adj. R-square & 0.8930 & & 0.8452 & \\
\hline Dep. Var. & log. Bids & & log. Bids & \\
\hline \#Auctions & 5,732 & & 5,732 & \\
\hline \#Bids & 13,809 & & 39,942 & \\
\hline
\end{tabular}

Table 3: OLS regression of the logarithmized dropout bid on a dummy variable indicating whether a bidder is a reseller. First specification is for the subsample of bids placed by resellers while second specification is for the subsample of bids placed by consumers. Auto fixed effects control for brand-model-fuel type-production year while auto controls include vehicle age, odometer reading, weight, horsepower, trim, turbo, all-wheel-drive and the mechanic ratings of the brakes, bodywork, engine, gearbox and interior. Number of bidders is instrumented by the first bid in an auction while the experience variables are both instrumented using the proportion of auctions the bidder has won up until the current auction. All standard errors are robust. Significance is given at the $10 \%(*), 5 \%(* *)$ and $1 \%(* * *)$ significance levels. 


\begin{tabular}{|c|c|c|c|c|c|}
\hline \multirow[b]{2}{*}{ Signal Component } & \multirow[b]{2}{*}{ Coefficient } & \multicolumn{2}{|c|}{ Model I } & \multicolumn{2}{|c|}{ Model II } \\
\hline & & Estimate & Std. Dev & Estimate & Std. Dev \\
\hline \multirow[t]{2}{*}{ Components of $\bar{a}$} & Constant & $9.51^{* * *}$ & $(0.2757)$ & $9.71^{* * *}$ & $(1.64)$ \\
\hline & \#Total Bidder Participation & $3.77 \mathrm{e}-05^{* * *}$ & $(6.26 \mathrm{e}-06)$ & $0.05^{* * *}$ & $(0.02)$ \\
\hline \multirow[t]{2}{*}{ Components of $\ln t$} & Constant & $-2.63^{* * *}$ & $(0.3423)$ & -1.80 & $(3.72)$ \\
\hline & Reseller & $1.22^{* * *}$ & $(0.3922)$ & 0.29 & $(0.61)$ \\
\hline \multirow[t]{6}{*}{ Components of $m$} & Constant $\S$ & & & & \\
\hline & Mint-Condition Value & $5.77 \mathrm{e}-06^{* * *}$ & $(2.42 \mathrm{e}-07)$ & $6.10 \mathrm{e}-06^{* * *}$ & $(2.06 \mathrm{e}-07)$ \\
\hline & Age & $-0.10^{* * *}$ & $(0.0026)$ & $-0.10^{* * *}$ & $(0.0021)$ \\
\hline & Odometer & $-4.03 \mathrm{e}-06^{* * *}$ & $(9.30 \mathrm{e}-07)$ & $-5.43 \mathrm{e}-06^{* * *}$ & $(1.82 \mathrm{e}-06)$ \\
\hline & Horse Power & $4.85 \mathrm{e}-04^{* * *}$ & $(7.09 \mathrm{e}-05)$ & $6.00 \mathrm{e}-04^{* * *}$ & $(0.0001)$ \\
\hline & Rating & $0.05^{* * *}$ & $(0.0031)$ & $0.04^{* * *}$ & $(0.0022)$ \\
\hline Components of $\ln r$ & Constant & 0.02 & $(0.4875)$ & -0.04 & $(3.1405)$ \\
\hline \multirow[t]{2}{*}{ Components of $\ln s$} & Constant & -0.31 & $(0.4763)$ & -0.46 & $(3.0299)$ \\
\hline & Reseller & $-0.68^{* * *}$ & $(0.0476)$ & $-0.77^{* * *}$ & $(0.0778)$ \\
\hline Dep. Var. & & log. Bids & & log. Bids & \\
\hline \#Auctions & & 5,732 & & 9,705 & \\
\hline \#Drop-out Prices & & 53,751 & & 95,869 & \\
\hline
\end{tabular}

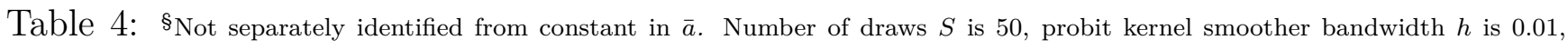
differencing-step size $\delta$ is 0.0001 . Results for the structural asymmetric ascending auction model. In model I, the fully filtered sample of auctions is used whereas in Model II, using the sample in which only auctions with large jump bids, jump bids that are higher than $20 \%$ of the highest bid, are removed. Resellers are defined as bidders that have won more than two car auctions during the sample period. Standard errors are calculated numerically using the formulas presented in Section 4 . Significance is given at the $10 \%(*), 5 \%$ $(* *)$ and $1 \%(* * *)$ significance levels. 


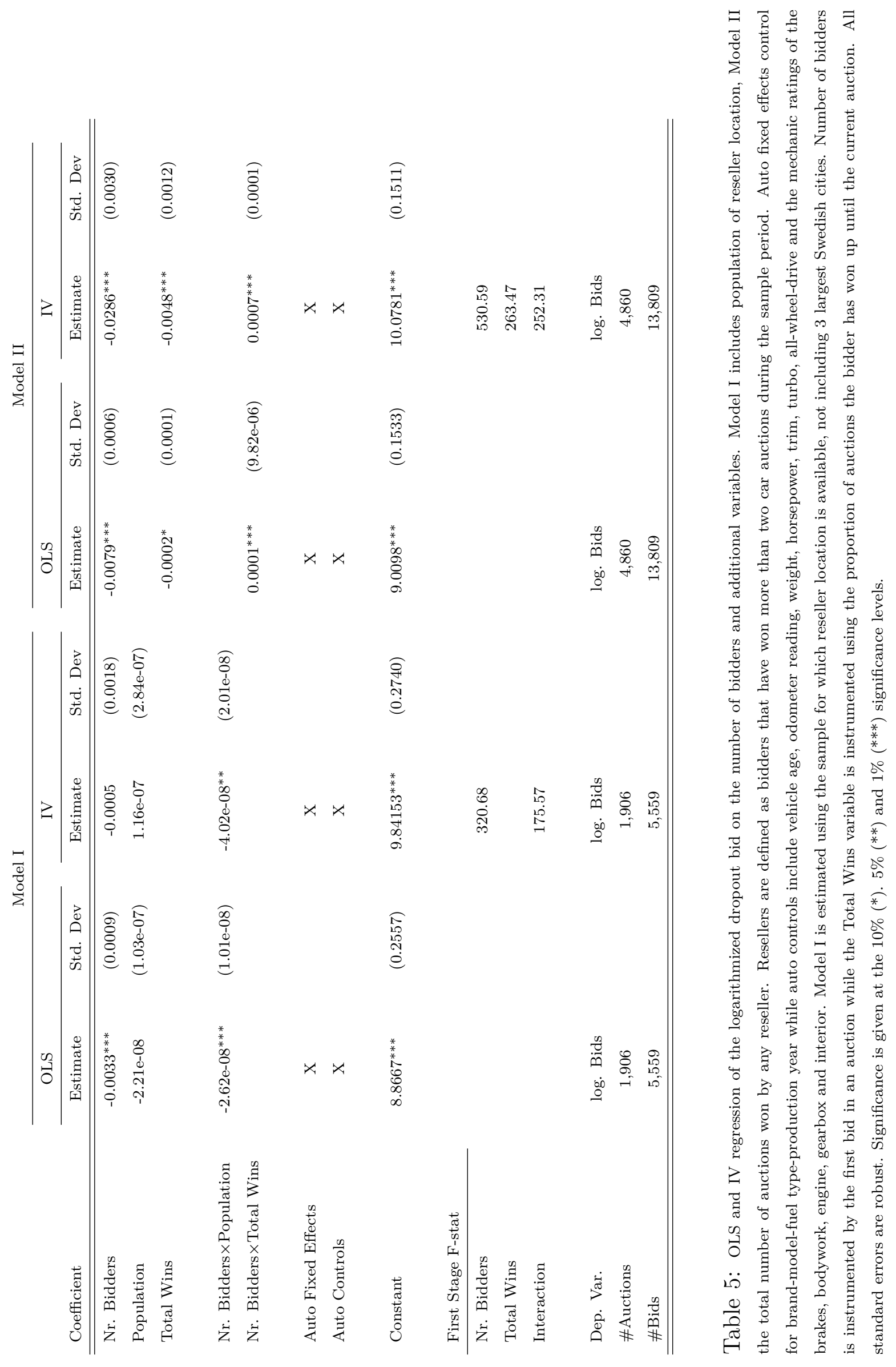


Model I

\begin{tabular}{|c|c|c|c|c|}
\hline \multirow[b]{2}{*}{ Coefficient } & \multicolumn{2}{|l|}{ OLS } & \multicolumn{2}{|l|}{ IV } \\
\hline & Estimate & Std. Dev & Estimate & Std. Dev \\
\hline Nr. Bidders & $-0.0066^{* * *}$ & $(0.0006)$ & $-0.0192^{* * *}$ & $(0.0013)$ \\
\hline Popular & -0.0201 & $(0.0137)$ & $-0.1227^{* * *}$ & $(0.0232)$ \\
\hline Nr. Bidders $\times$ Popular & $0.0024^{* * *}$ & $(0.0009)$ & $0.0108^{* * *}$ & $(0.0019)$ \\
\hline Auto Fixed Effects & $\mathrm{X}$ & & $\mathrm{X}$ & \\
\hline Auto Controls & $\mathrm{X}$ & & $\mathrm{X}$ & \\
\hline Constant & $9.6485^{* * *}$ & $(0.1609)$ & $9.7951^{* * *}$ & $(0.1210)$ \\
\hline \multicolumn{5}{|l|}{ First Stage F-stat } \\
\hline Nr. Bidders & & & 955.92 & \\
\hline Interaction & & & 373.41 & \\
\hline Dep. Var. & log. Bids & & log. Bids & \\
\hline \#Auctions & 4,860 & & 4,860 & \\
\hline \#Bids & 13,809 & & 13,809 & \\
\hline
\end{tabular}

Table 6: OLS and IV regression of the logarithmized dropout bid on the number of bidders and additional variables. Model I includes a dummy for the two most popular car models in the sample - the Volvo V70 and the Volkswagen Passat. Sample only includes bids placed by resellers. Resellers are defined as bidders that have won more than two car auctions during the sample period. Auto fixed effects control for brand-model-fuel type-production year while auto controls include vehicle age, odometer reading, weight, horsepower, trim, turbo, all-wheel-drive and the mechanic ratings of the brakes, bodywork, engine, gearbox and interior. Model I includes brand-fuel type-production year, not including model fixed effects as in the other models. Number of bidders is instrumented by the first bid in an auction while the Total Wins variable is instrumented using the proportion of auctions the bidder has won up until the current auction. All standard errors are robust. Significance is given at the $10 \%(*) .5 \%(* *)$ and $1 \%(* * *)$ significance levels. 


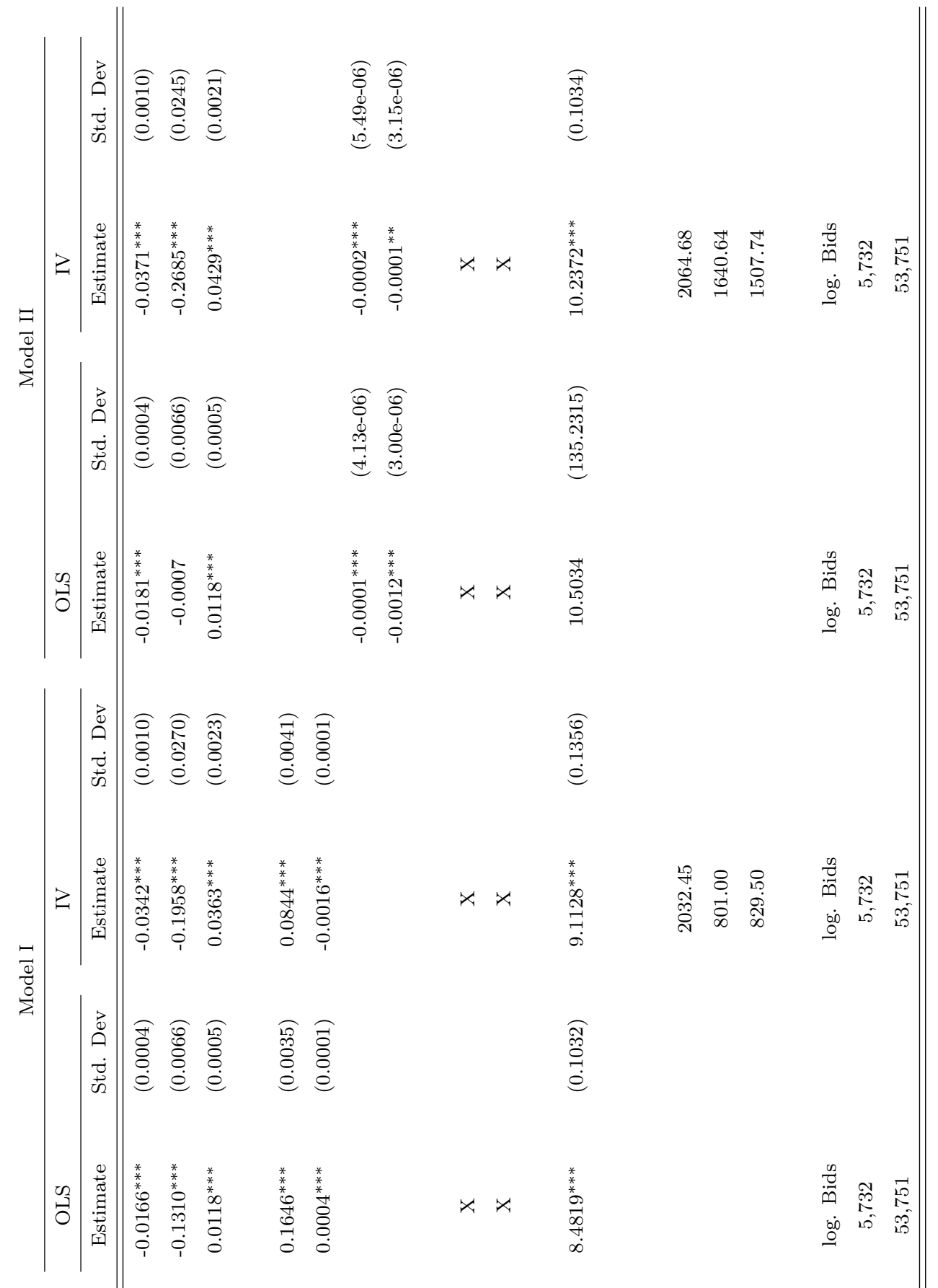

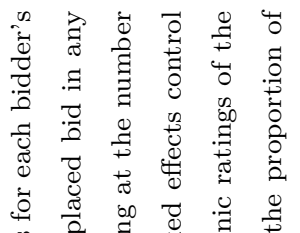

褐

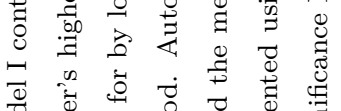

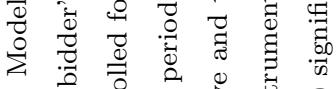

它

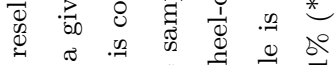

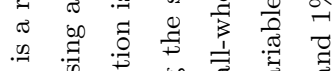

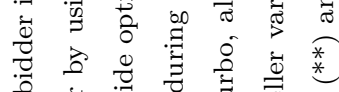

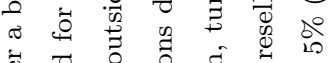

莺

范

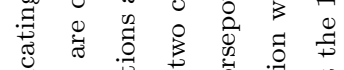

节

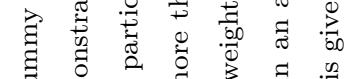

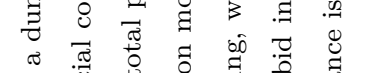

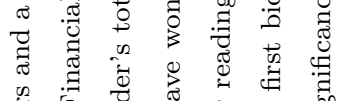

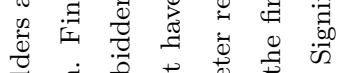

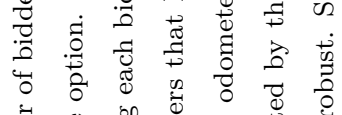

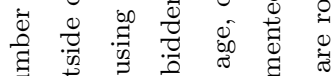

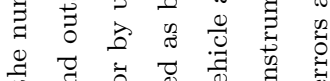

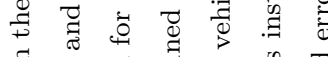

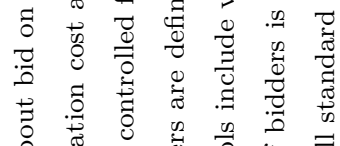

各. :

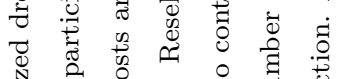

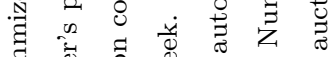

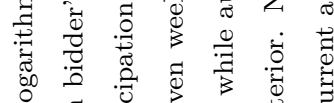

足

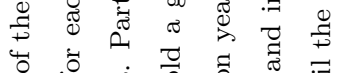

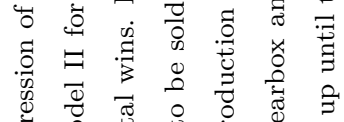

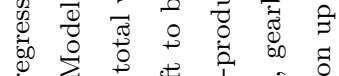

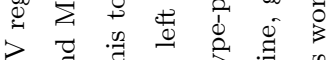

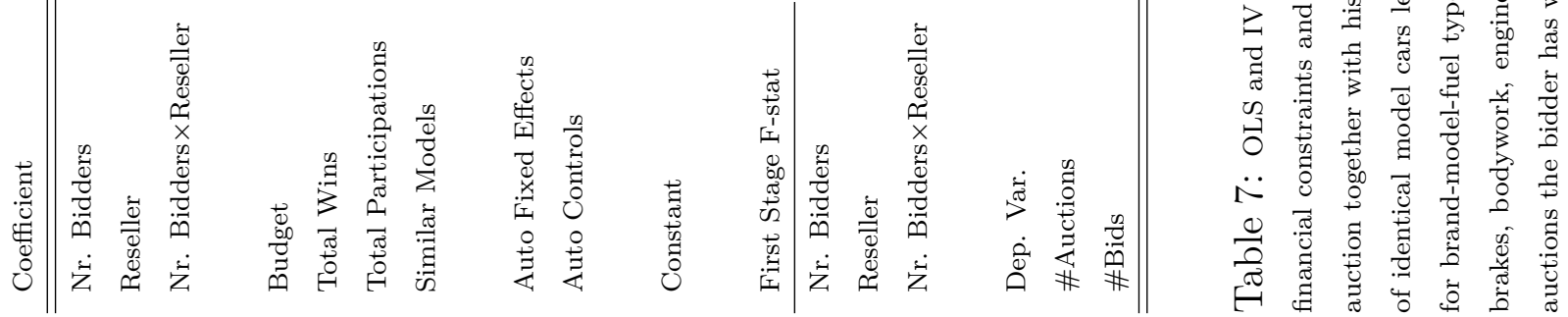




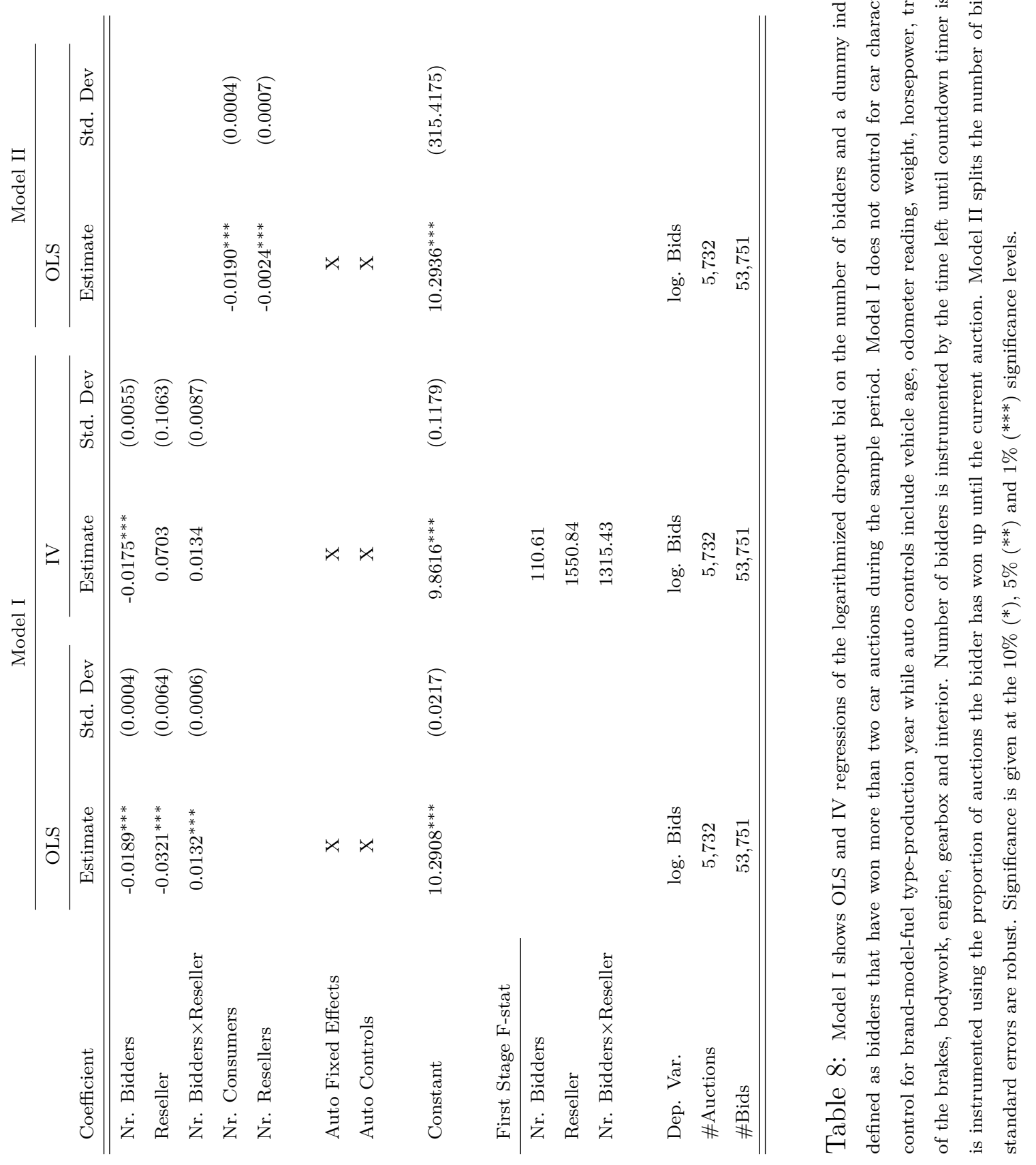



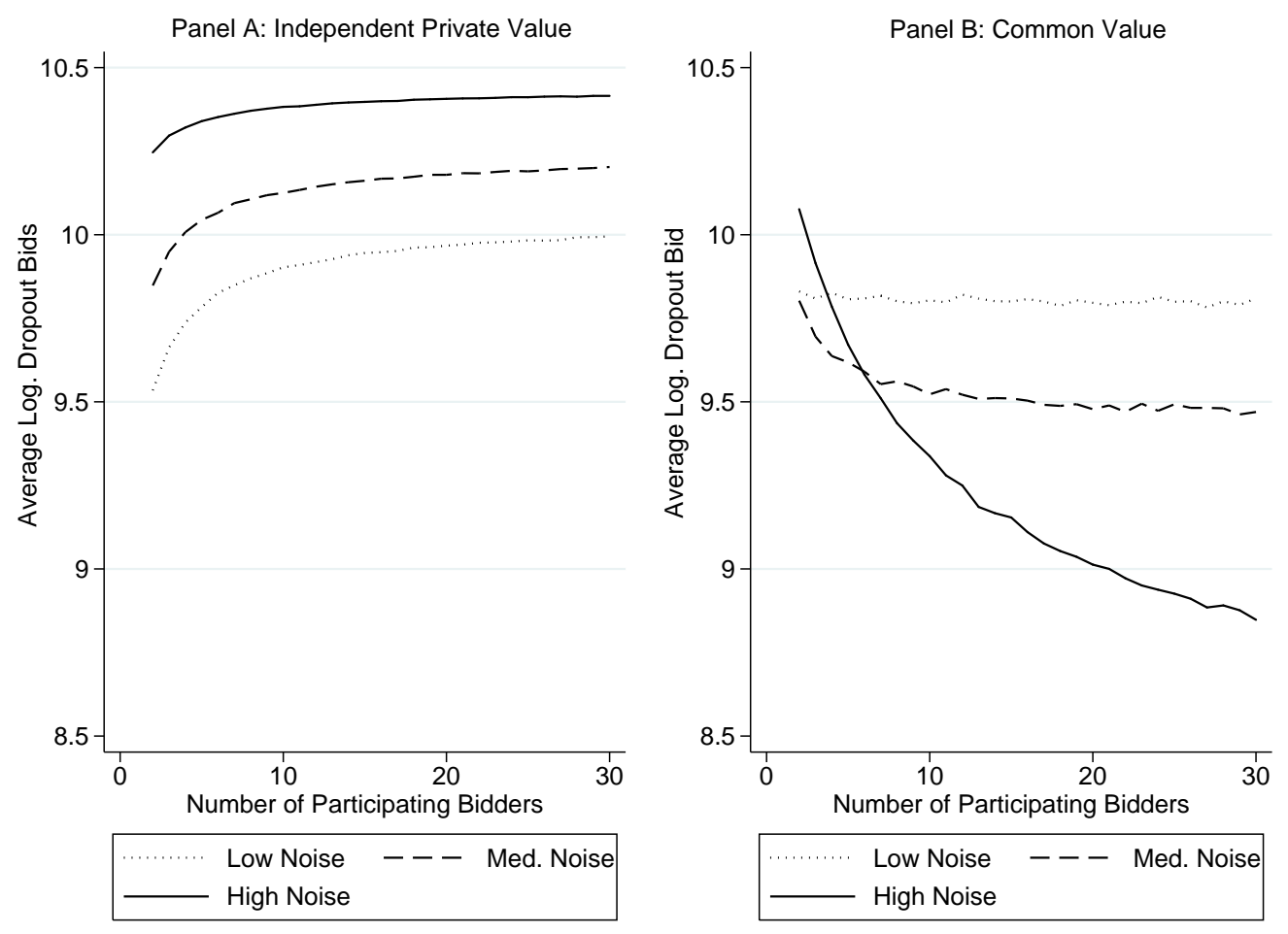

Figure 1: Simulated average bids for 10,000 auctions plotted against the number of participating auction bidders. In the Panel $\mathrm{A}$, bidder valuations contain a large independent private value component, $\left(\theta_{a}=10, \theta_{t}=0, \theta_{m}=0, \theta_{r}=-10, \theta_{s} \in\{-2,0,2\}\right)$. In Panel $\mathrm{B}$, bidder valuations contain a large common value component, $\left(\theta_{a}=10, \theta_{t}=-10, \theta_{m}=0, \theta_{r}=0, \theta_{s} \in\{-2,0,2\}\right)$. 

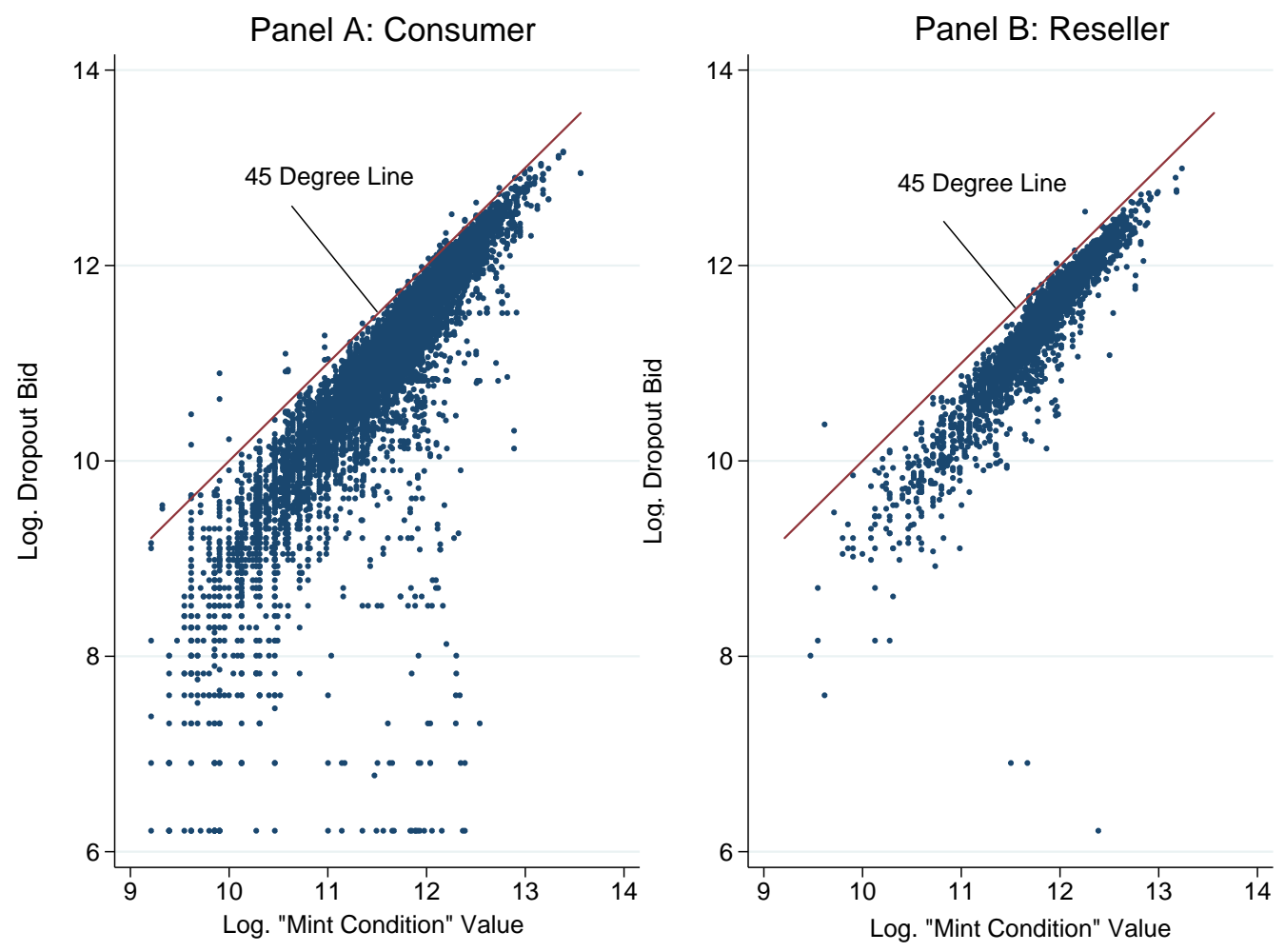

Figure 2: Panel A shows logarithmized dropout bids plotted against logarithmized "Mint Condition" values for consumers whereas Panel B is that logarithmized dropout bids for resellers of logarithmized "Mint Condition" values plotted against. Solid lines are the 45-degree line. 


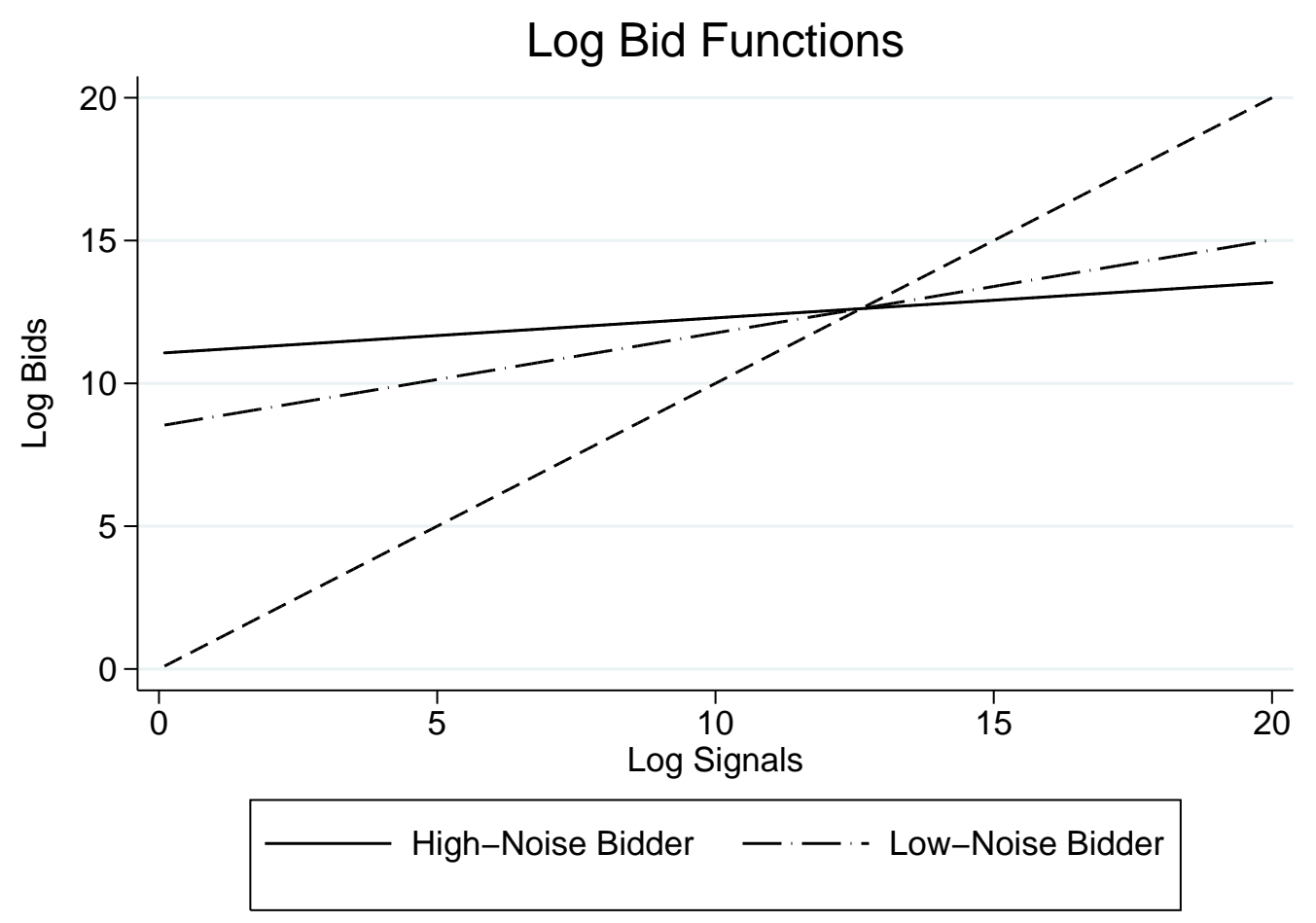

Figure 3: Estimated bid functions for two generic bidders one of which has a lot of previous experience (Low-Noise Bidder) and the other that has no previous experience (High-Noise Bidder). High experience reduces value signal noise resulting in experienced bidders bidding closer to the 45-degree line. 


\section{Log Bid Functions}

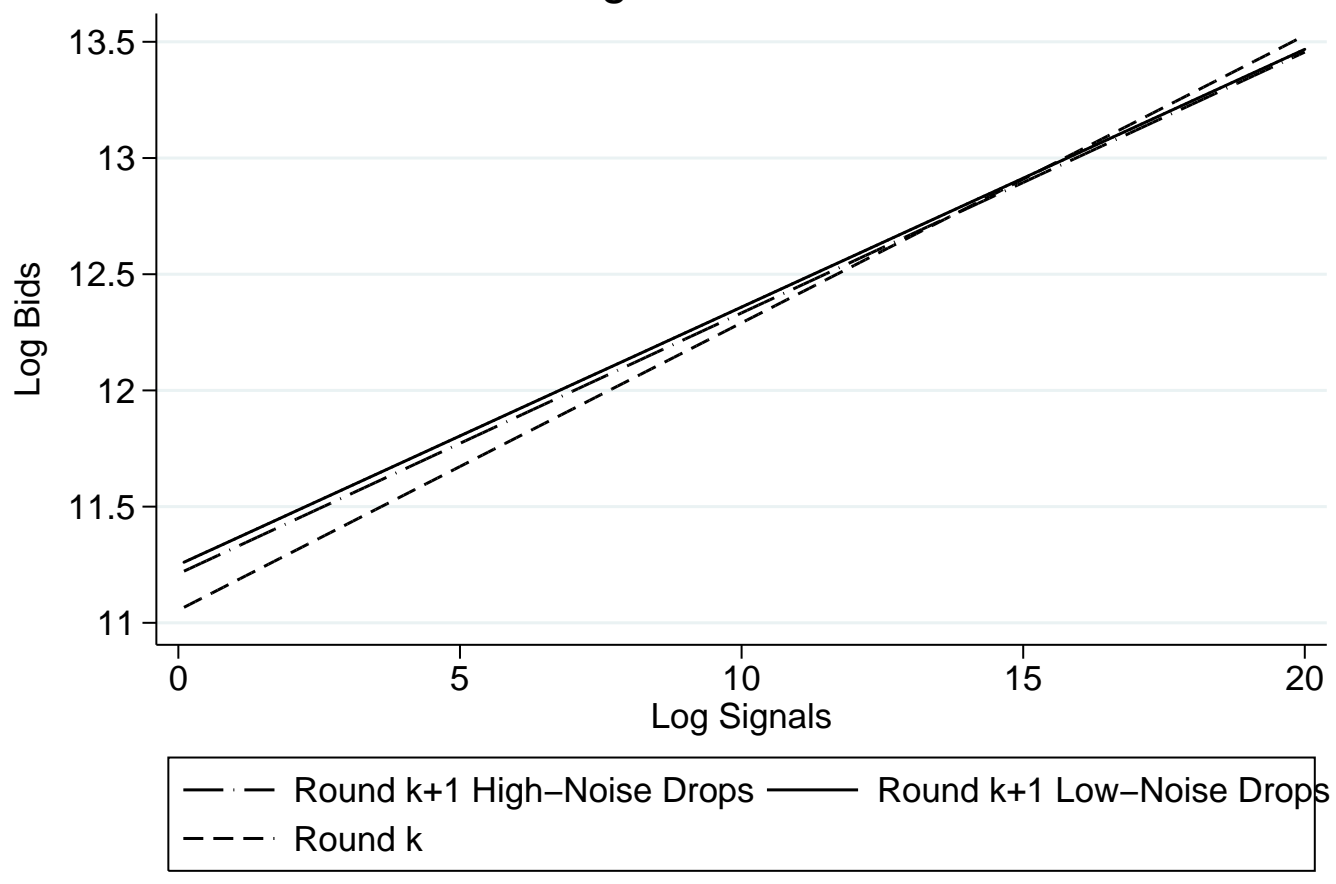

Figure 4: Estimated bid functions for round $k$ and updated round $k+1$ of a generic bidder, one after having observed an experienced (Low-Noise) bidder drop out in round $k$ and one after having observed an inexperienced (High-Noise) bidder drop out in round $k$. 


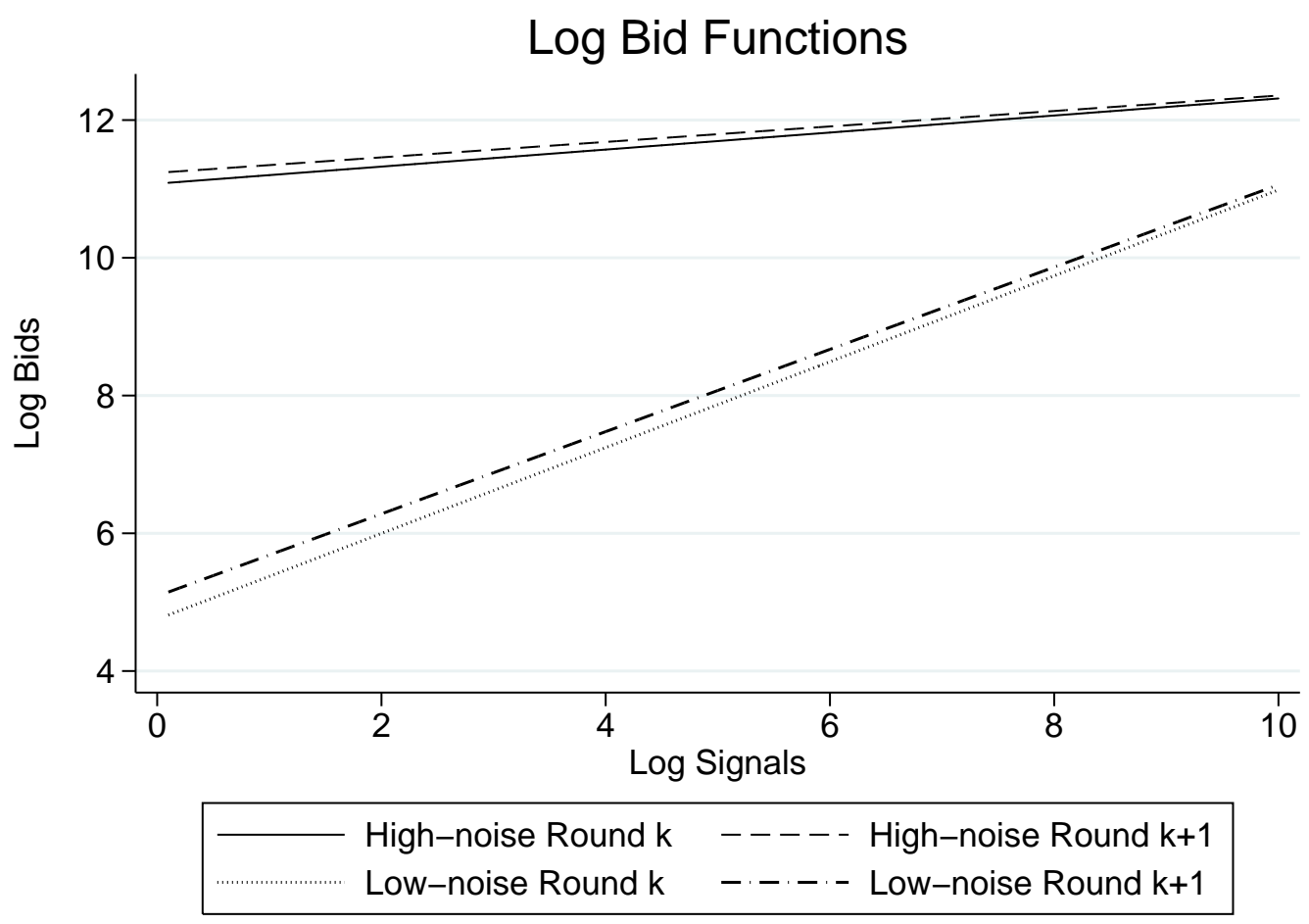

Figure 5: Estimated bid functions for rounds $k$ and $k+1$ of two generic bidders one of which has a lot of previous experience (Low-Noise Bidder) and the other that has no previous experience (High-Noise Bidder) after having observed a generic bidder drop out in round $k$. 


\section{Counterfactual: More Information}
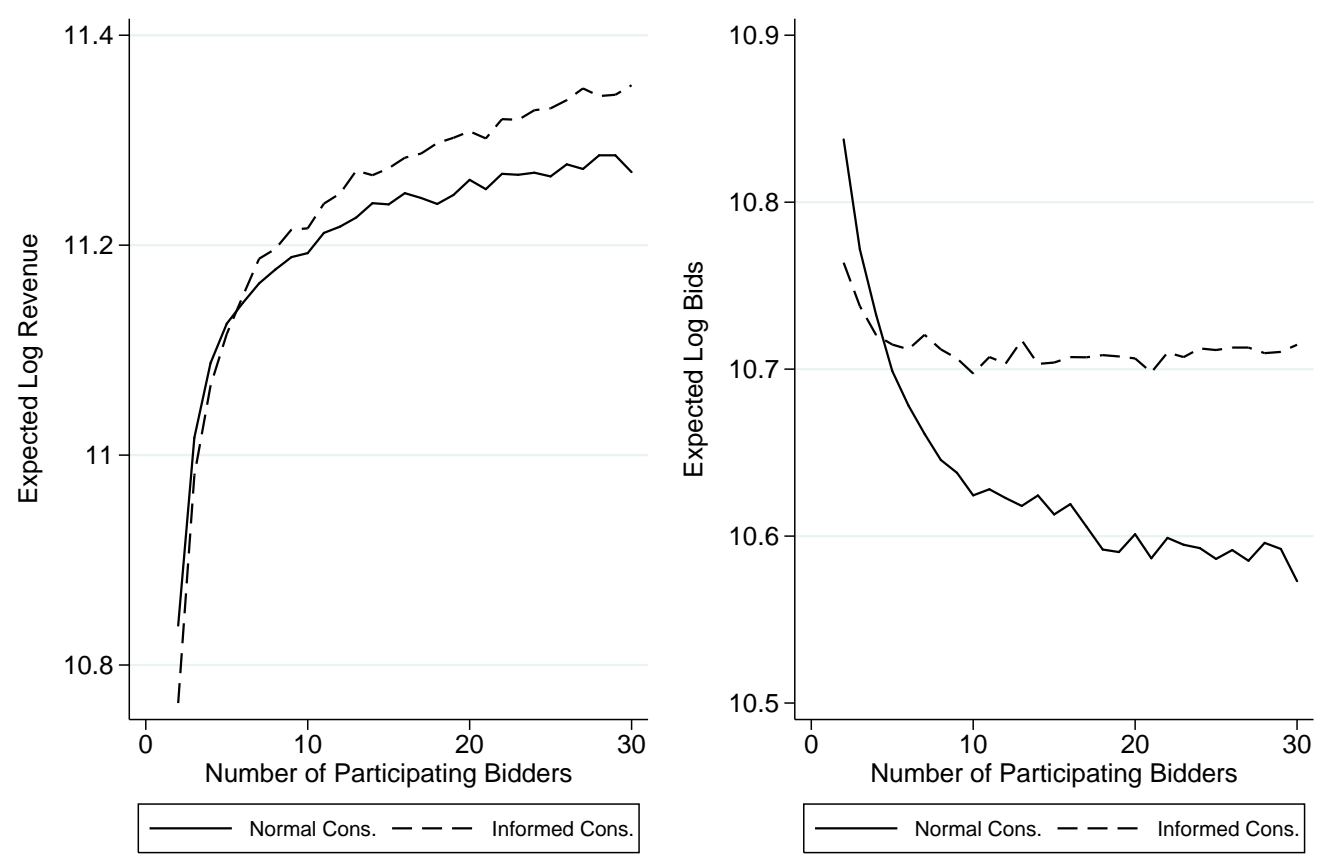

Figure 6: Simulated average revenues and average bids for 100,000 auctions. Parameters used for simulation are those of Model I from Table 4. Panel A shows how the average revenues from the auction of a vehicle with sample average car characteristics change if consumers were given the same signal precision as resellers. Solid line shows average revenues in the case when all bidders are normal consumers whereas the dashed line when all bidders are instead consumers with the signal precision of resellers. Panel B shows how average bids from the auction of a vehicle with sample average car characteristics change with the signal precision of consumers. 


\section{Counterfactual: Subsidies}
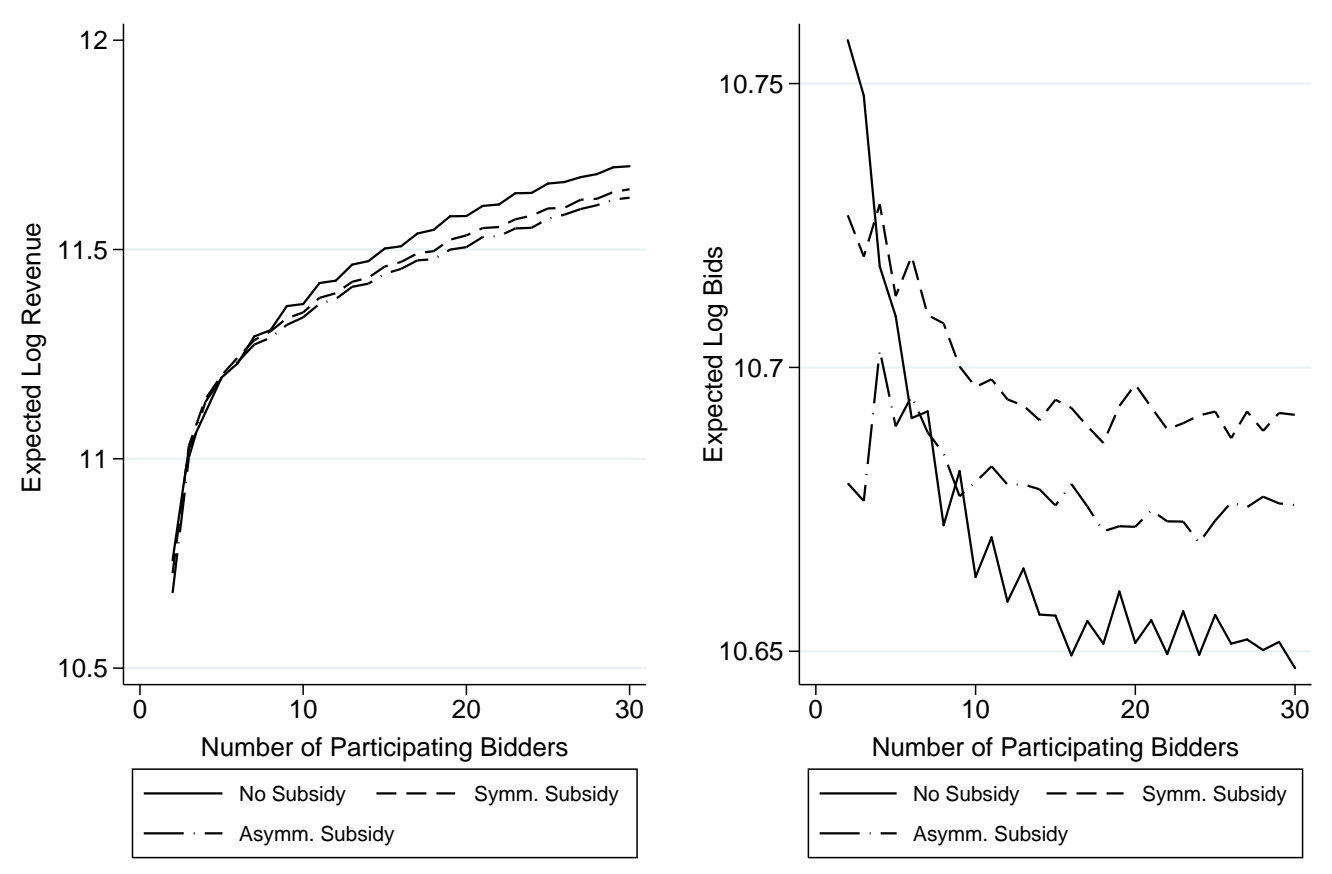

Figure 7: Simulated average revenues and average bids for 100,000 auctions. Parameters used for simulation are modified versions those of Model I from Table 4 and described in more detail in Section 7. Panel A shows how the average revenues from the auction of a vehicle with sample average car characteristics change if consumers were given a subsidy at the expense of resellers. Solid line shows average revenues in the case when all consumers are normal consumers whereas the dashed line when all consumers are instead subsidized $5 \%$ of car value at the expense of resellers. The longer-dashed line shows revenues when all consumers are instead subsidized $5 \%$ of car value while resellers are charged $7.5 \%$. Panel B shows how average bids from the auction of a vehicle with sample average car characteristics change with the the introduction of a subsidy to consumers and fee to resellers. 


\section{Counterfactual: All-Reseller Auctions}
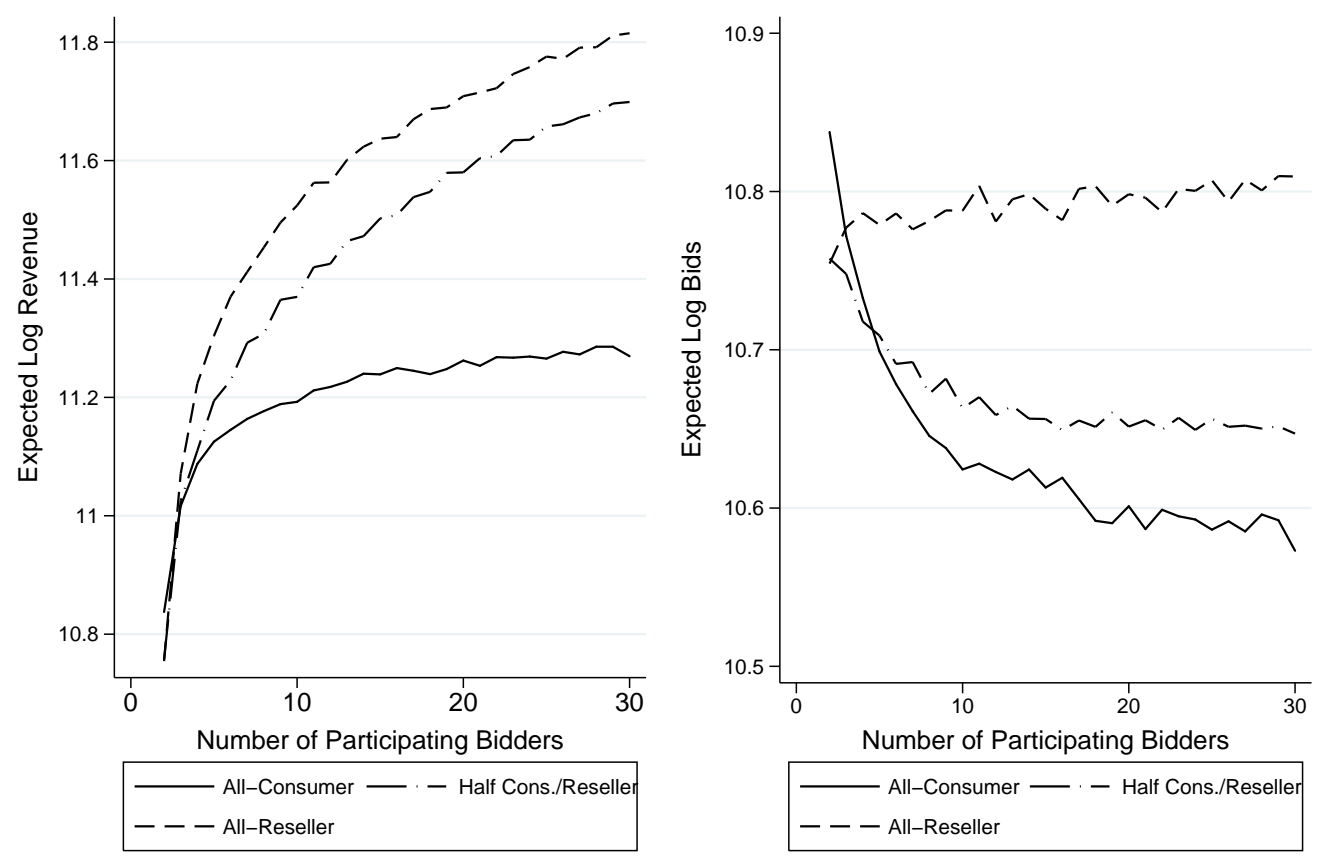

Figure 8: Simulated average revenues and average bids for 100,000 auctions. Parameters used for simulation are those of Model I from Table 4. Panel A shows how the average revenues from the auction of a vehicle with sample average car characteristics change if consumers were allowed to participate in all-reseller auctions. Solid line shows average revenues in the case when all auction participants are consumers, the dashed line when there are 50\% consumers and 50\% resellers, and the dashed line when all auction participants are resellers. Panel B shows how average bids from the auction of a vehicle with sample average car characteristics change with the the introduction of consumers into all-resellers auctions. 


\section{Data}

Tables 4 through 7 below, give a brief description of all information publicly provided for each vehicle listed for auction on the Swedish online auction site from which the data is taken for this study. ${ }^{45}$ Although, the format is standardized, this does not necessarily guarantee that all details are provided without flaw. For instance, the Swedish Transport Agency's vehicle register, from which a vehicle's technical details are collected, contains more information about newer vehicles, meaning that older vehicles will may lack certain information. Furthermore, mechanics sometimes do not assess all aspects of the vehicle, rating them "Unknown" or "Untested"46

\begin{tabular}{c|l} 
Transaction and Misc. Variables & Description \\
\hline \hline Transaction Price & The price paid for the vehicle in SEK, not incl. the auction fee. \\
Uuction Date and Time & Username of winning bidder. \\
Appraised Value & Date and time at which the final countdown starts. \\
The appraised value of the vehicle. \\
Region of Sale & $\begin{array}{l}\text { The location of the warehouse at which the } \\
\text { vehicle is situated. } \\
\text { Bhe appraised replacement price for the given } \\
\text { Seller Type } \\
\text { vehicle model. } \\
\text { Broad categorization of the type of seller e.g. Fleet } \\
\text { Owner, Insurance company or Governmental agency. } \\
\text { These contain detailed comments about the expert's assessment } \\
\text { of the vehicle as well as any major/minor details of interest. }\end{array}$ \\
\hline \hline
\end{tabular}

Table 9: Description of transaction and miscellenious variables provided by the Swedish online auction house for each vehicle auctioned. This information is listed for every vehicle auctioned from the time the vehicle is listed.

\footnotetext{
${ }^{45}$ This description is valid for the data collected up until Dec. 31st 2012. From Jan. 1st 2013, the site changed the standardized format somewhat with certain information being added and other information being removed.

${ }^{46}$ Most often this is for vehicles that have been in a car accident and are sold as "objects for repair" or for spare parts.
} 


\begin{tabular}{|c|c|}
\hline Technical Variables & Description \\
\hline Equipment & $\begin{array}{l}\text { A detailed list of equipment available in the car } \\
\text { e.g. GPS, Parking Assistance. }\end{array}$ \\
\hline Odometer Reading & $\begin{array}{l}\text { The odometer reading of the car at the time of sale } \\
\text { in tens of kilometers. }\end{array}$ \\
\hline Colour and Coating Type & $\begin{array}{l}\text { Colour of the vehicle and whether the coating } \\
\text { is matte or solid. }\end{array}$ \\
\hline Engine Power (Kw and HP) & The engine size given in both $\mathrm{KW}$ and horse power. \\
\hline Fuel type & The type of fuel the vehicle is registered to run on. \\
\hline Hook & Whether the vehicle is fitted with a tow hook. \\
\hline Fuel Economy & $\begin{array}{l}\text { Fuel economy of the vehicle based on mixed driving } \\
\text { conditions in litres per } 100 \mathrm{~km} \text {. }\end{array}$ \\
\hline CO2 Emissions & $\begin{array}{l}\text { The amount of } \mathrm{CO} 2 \text { the vehicle emits is grams per } \\
\text { kilometer. }\end{array}$ \\
\hline Number of Passengers & $\begin{array}{l}\text { The number of passengers the vehicle is legally } \\
\text { registered to carry. May differ from the technical } \\
\text { specification of the vehicle. }\end{array}$ \\
\hline Number of Keys & Number of keys accompanying vehicle. \\
\hline $\begin{array}{l}\text { Total Allowed Weight } \\
\text { Max Allowed Load }\end{array}$ & $\begin{array}{l}\text { The total weight legally allowed for the vehicle in kilograms. } \\
\text { The maximal load the vehicle is allowed to carry in kilograms. }\end{array}$ \\
\hline
\end{tabular}

Table 10: Description of technical variables provided by auction site for each vehicle auctioned. This information is listed for every vehicle auctioned from the time the vehicle is listed. 


\begin{tabular}{|c|c|}
\hline Legal Variables & Description \\
\hline Registration and Chassis Numbers & Vehicle registration number and chassis number. \\
\hline Production Month and Year & $\begin{array}{l}\text { Year and month the vehicle rolled off the } \\
\text { production line. }\end{array}$ \\
\hline Date of Vehicle Registration & $\begin{array}{l}\text { Year and month the vehicle was registered with } \\
\text { the Swedish Transport Agency. }\end{array}$ \\
\hline Date of Entering into Traffic & $\begin{array}{l}\text { Year and month the vehicle entered into traffic } \\
\text { in Sweden. }\end{array}$ \\
\hline MOT $^{\S}$ Test Period & $\begin{array}{l}\text { The period within a year during which a vehicle } \\
\text { must be inspected. }\end{array}$ \\
\hline Date of Last MOT Test & $\begin{array}{l}\text { The date and result of last MOT inspection. A failed } \\
\text { inspection is reported together with flaws found and } \\
\text { date before which the problems must be resolved. } \\
\text { A number of vehicles are banned from being in traffic. } \\
\text { The annual road tax the owner of the vehicle has }\end{array}$ \\
\hline Annual Tax & $\begin{array}{l}\text { to pay. Depends on the weight, } \mathrm{CO} 2 \text { emissions, } \\
\text { environmental classification, fuel type, municipality of } \\
\text { registration and gearbox type. }\end{array}$ \\
\hline Environmental Classification & $\begin{array}{l}\text { The environmental classification of the vehicle based } \\
\text { on EU emission standards. }\end{array}$ \\
\hline Tax Deductability & $\begin{array}{l}\text { Whether it is possible to deduct the annual tax if } \\
\text { purchased for corporate use. }\end{array}$ \\
\hline Imported & $\begin{array}{l}\text { Whether the vehicle is imported or originally } \\
\text { sold in Sweden. }\end{array}$ \\
\hline Export Permissible & Whether the vehicle can be exported or not. \\
\hline Temporary Registration Permissible & $\begin{array}{l}\text { Whether it is possible to temporarily register the vehicle } \\
\text { for export. Legally, if not possible, the vehicle cannot be } \\
\text { driven on Swedish roads as the Swedish registration } \\
\text { number is removed. }\end{array}$ \\
\hline
\end{tabular}

Table 11: $§$ MOT, is a British terms which stands for Ministry of Transport and the MOT test is conducted to assess whether a vehicle is roadworthy. The Swedish counterpart is called the "Roadworthiness test". Description of legal and administrative variables provided by auction site for each vehicle auctioned. This information is listed for every vehicle auctioned from the time the vehicle is listed. 


\begin{tabular}{|c|c|}
\hline Quality Variables & Description \\
\hline Service Book and History & $\begin{array}{l}\text { Whether the car comes with its original service book } \\
\text { and if so, an exerpt of the service history. }\end{array}$ \\
\hline Bodywork, Engine, Gearbox, Brakes & Experts assessment based on a 1-5 scale with \\
\hline and Interior Ratings & 5 being best and 1 being worst. \\
\hline Vehicle Guarantee & $\begin{array}{l}\text { Details of any remaining guarantees that were issued on the } \\
\text { new vehicle. }\end{array}$ \\
\hline Damage Guarantee & $\begin{array}{l}\text { Details of any remaining damage guarantees that were issued } \\
\text { on the new vehicle. If a damage guarantee still covers the } \\
\text { vehicle one has benefits on the insurance premium one } \\
\text { pays for the vehicle. }\end{array}$ \\
\hline
\end{tabular}

Table 12: Description of quality and assessment variables provided by auction site for each vehicle auctioned. This information is listed for every vehicle auctioned from the time the vehicle is listed. 